\title{
Molecular Entrapment of Polymers by Pyrogallol[4]arenes
}

\author{
Li Shao ${ }^{\S}$, Hanwen Zhang ${ }^{\#}$, Xiaoqing He ${ }^{\star}$, Bin Hua ${ }^{* \dagger}$, Xiangquan Hu ${ }^{\S}$, Caixia Wan $^{\#}$, Steven P. Kelley ${ }^{\S}$, \\ and Jerry L. Atwood* $*^{s}$ \\ ${ }^{\S}$ Department of Chemistry, University of Missouri, Columbia, Missouri 65211, United States \\ \# Department of Biomedical, Biological \& Chemical Engineering, University of Missouri, Columbia, \\ Missouri 65211, United States \\ ${ }^{\&}$ Electron Microscopy Core Facility, University of Missouri, Columbia, Missouri 65211, United States \\ tDepartment of Chemistry, Zhejiang University, Hangzhou 310027, P. R. China \\ Email: huabin@zju.edu.cn; Atwoodj@missouri.edu
}

\section{Supporting Information (28 pages)}

1. Materials and methods

2. The photographs of the host-guest complex coprecipitates of $\mathbf{P g C} \boldsymbol{C}_{3}$ and PEG with different molecular weights

3. ${ }^{1} H$ NMR spectra of the coprecipitates of $P g C_{3}$ and $P E G$ with different molecular weights

4. Enlarged magic angle spinning $2 D$ heterocorrelated NMR spectrum of $\mathrm{PgC}_{3} \supset P E G$

5. FTIR spectra of $P g C_{3}, P E G$ and the complexes between $P g C_{3}$ and PEG with different molecular weights in solution

6. Stoichiometry determination for the complexation between $\boldsymbol{P g C}_{3}$ and PEG with different molecular weights.

7. Association constant determination for the complexation between $\mathbf{P g C}_{3}$ and diethylene glycol

8. The 2D NMR NOESY spectrum of PEG and $\mathrm{PgC}_{3}$

9. ITC investigations of host-guest complexation between PEG and $P g C_{3}$

10. Crystal structures of $P g C_{3} \supset E G, P g C_{3} \supset T E G$ and $P g C_{3} \supset$ TetraEG

11. Packing model of $\boldsymbol{P g} \boldsymbol{C}_{3}$ in the crystal structure

12. Time-dependent ${ }^{1} H$ NMR of PEG with different molecular weights in $\mathrm{D}_{2} \mathrm{O}$ in the presence of $\boldsymbol{P g C} \boldsymbol{C}_{3}$ 
13. $X$-ray crystal data of $P g C_{3} \supset E G, P g C_{3} \supset T E G$ and $P g C_{3} \supset$ TetraEG

14. References

S28 


\section{Materials and methods}

\section{Materials}

All reagents were commercially available and used as supplied without further purification. Solvents were either employed as purchased or dried according to procedures described in the literature. Compound $\mathbf{P g C}_{\mathbf{3}}$ are synthesized according to previous literature. ${ }^{[\mathrm{S} 1]}$

\section{NMR analyses}

All NMR studies were conducted on the Bruker DRX600 or Bruker DRX500 instrument at University of Missouri (MU) with a $5 \mathrm{~mm}$ tube. Samples were dissolved in deuterated solvents.

\section{Crystallographic data}

Single-crystal XRD (SCXRD) data for $\mathbf{P g C}_{3} \supset \mathbf{E G}$ were collected on a Bruker X8 Prosepctor diffractometer equipped with an Apex II CCD area detector using $\mathrm{Cu}-\mathrm{K} \alpha$ radiation $\left(\lambda=1.54178 \AA\right.$ ) from a microfocus source. SCXRD data for $\mathbf{P g C}_{3} \supset$ TEG crystals were cooled to $100 \mathrm{~K}$ during collection using Cyrostream 700 cryostats (Oxford Cryosystems, Oxford, UK). Hemispheres of data were collected out to a resolution of at least $0.80 \AA$ using strategies of scans about the phi and omega axes. Data collection, unit cell determination, data reduction, absorption correction and scaling, and space group determination were done using the Apex3 software suite. ${ }^{[\mathrm{S} 2]}$

$\mathbf{P g C}_{3} \supset \mathbf{E G}$ was solved by direct methods as implemented in SHELXS. ${ }^{[\mathrm{S} 3]} \mathbf{P g C}_{3} \supset \mathbf{T E G}$ was solved using an iterative dual space approach as implemented in SHELXT. ${ }^{[\mathrm{S} 4]}$ Olex $2^{[\mathrm{S} 5]}$ was used for model visualization and as an interface for refinement programs, and CCDC Mercury ${ }^{\left[{ }^{[6]}\right]}$ was used to analyze packing, calculate powder diffractograms, and visualize Miller planes. Full-occpancy non-hydrogen atoms were located from the difference map and refined anisotropically. Hydrogen atoms bonded to oxygen could be located from the difference map; their coordinates were refined freely while their thermal parameters were constrained to ride on the carrier atom. Hydrogen atoms bonded to carbon were placed in calculated positions, and their thermal parameters and coordinates were constrained to ride on the carrier atoms. Methyl group hydrogen atoms were refined with a riding-rotating model. Disordered groups in $\mathbf{P g C}_{3} \supset$ TEG were modeled by locating both parts from the difference map and constraining their occupancies at fixed values. Minor parts were refined isotropically and required distance restraints in some cases. 
The final model contains a B-level PLAT097 alert due to residual electron density associated with a disordered part that could not be modeled because it overlaps too closely with the major part. A B-level PLAT043 alert also occurs due to unrealistically close contacts between one of the minor parts of a disordered molecule and a full-occupancy group which is also likely affected by unmodeled disorder. These issues are common in modeling of disordered structures and do not impact the interpretation of the structure.

\section{FTIR analyses}

FTIR experiments were conducted on Nicolet Summit FTIR Spectrometer at MU.

\section{ITC analyses}

Isothermal titration calorimetric (ITC) experiments were performed on a VP-ITC micro-calorimeter in $298 \mathrm{~K}$.

\section{DSC analyses}

DSC analyses were performed on TA instruments Q100 ${ }^{\mathrm{TM}}$ at MU. About $2 \mathrm{mg}$ of sample was placed into a tared DSC closed aluminum pan and the weight of the sample was accurately recorded. Change in heat flow was plotted against temperature ranging from 40 to $250{ }^{\circ} \mathrm{C}$.

\section{PXRD analyses}

PXRD data were collected on a Bruker D8 Venture diffractometer using Mo-K $\alpha$ radiation $(\lambda=0.7179 \AA)$ from a microfocus source.

\section{Solid-state NMR analyses}

Solid-state nuclear magnetic resonance (NMR) spectra were recorded on a BRUKER 400M WB AVANCE III spectrometer.

\section{GPC analyses}

GPC analyses were performed on an Agilent 1200 series high performance liquid chromatography (HPLC) system (Agilent Technologies, Palo Alto, CA) equipped with a refractive index (RI) detector and an Agilent PLgel $5 \mu \mathrm{m}$ MIXED-D column 
$(300 \times 7.5 \mathrm{~mm})$. Both refractive index detector (RID) and column temperatures were maintained at $35{ }^{\circ} \mathrm{C}$. THF with a flow rate of $1 \mathrm{~mL} / \mathrm{min}$ was used as the eluent. Commercially available PEGs with molecular weights of 2000, 4000, 6000, 8000, 10000 were used for calibration.

\section{Preparation of $\mathrm{PgC}_{3} \supset \mathrm{PEG}$ coprecipitates}

$0.100 \mathrm{~g}$ of $\mathbf{P g C}_{3}$ and $0.010 \mathrm{~g}$ of PEG was individually dissolved in $5 \mathrm{~mL} \mathrm{CH}_{3} \mathrm{CN}$. The solutions were mixed and sonicated until well combined and then put in room temperature. The host-guest coprecipitates were formed and collected and washed with $\mathrm{CH}_{3} \mathrm{CN}$ for three times to remove the uncomplexed molecules.

\section{Synthesis and Crystallization of $\mathrm{PgC}_{3} \supset \mathrm{EG}, \mathrm{PgC}_{3} \supset$ TEG and $\mathrm{PgC}_{3} \supset$ TetraEG}

$0.030 \mathrm{~g}$ of $\mathbf{P g C}_{3}$ and $0.100 \mathrm{~g}$ of EG or TEG or TetraEG was dissolved in $1 \mathrm{~mL}$ $\mathrm{CH}_{3} \mathrm{CN}$. The solutions were sonicated until well combined and then put in room temperature. Colorless and transparent crystals were formed and collected for single crystal X-ray analysis.

2. The photographs of the host-guest complex coprecipitates of $\boldsymbol{P g C}_{3}$ and PEG with different molecular weights
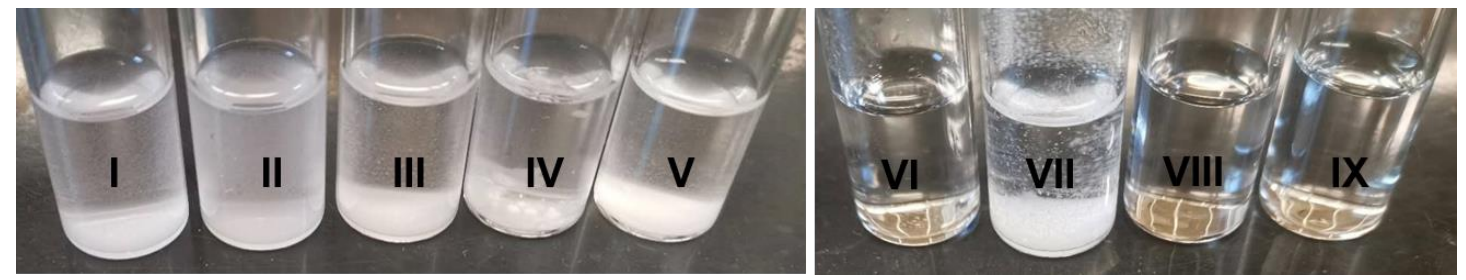

Figure S1. Photographs of the host-guest complex coprecipitates of $\mathbf{P g C}_{\mathbf{3}}$ and PEG with molecular weights of 2000 (I), 4000 (II), 6000 (III), 8000 (IV) and 10000 (V) in acetonitrile. The photographs of $\mathbf{P g C}_{\mathbf{3}}$ (VI), PgC $\mathbf{3}$ and PEG10000 (VII), pyrogallol and PEG10000 (VIII), PEG10000 (IX) in acetonitrile.

\section{3. ${ }^{1} H$ NMR spectra of the coprecipitates of $P g C_{3}$ and PEG with different molecular weights}




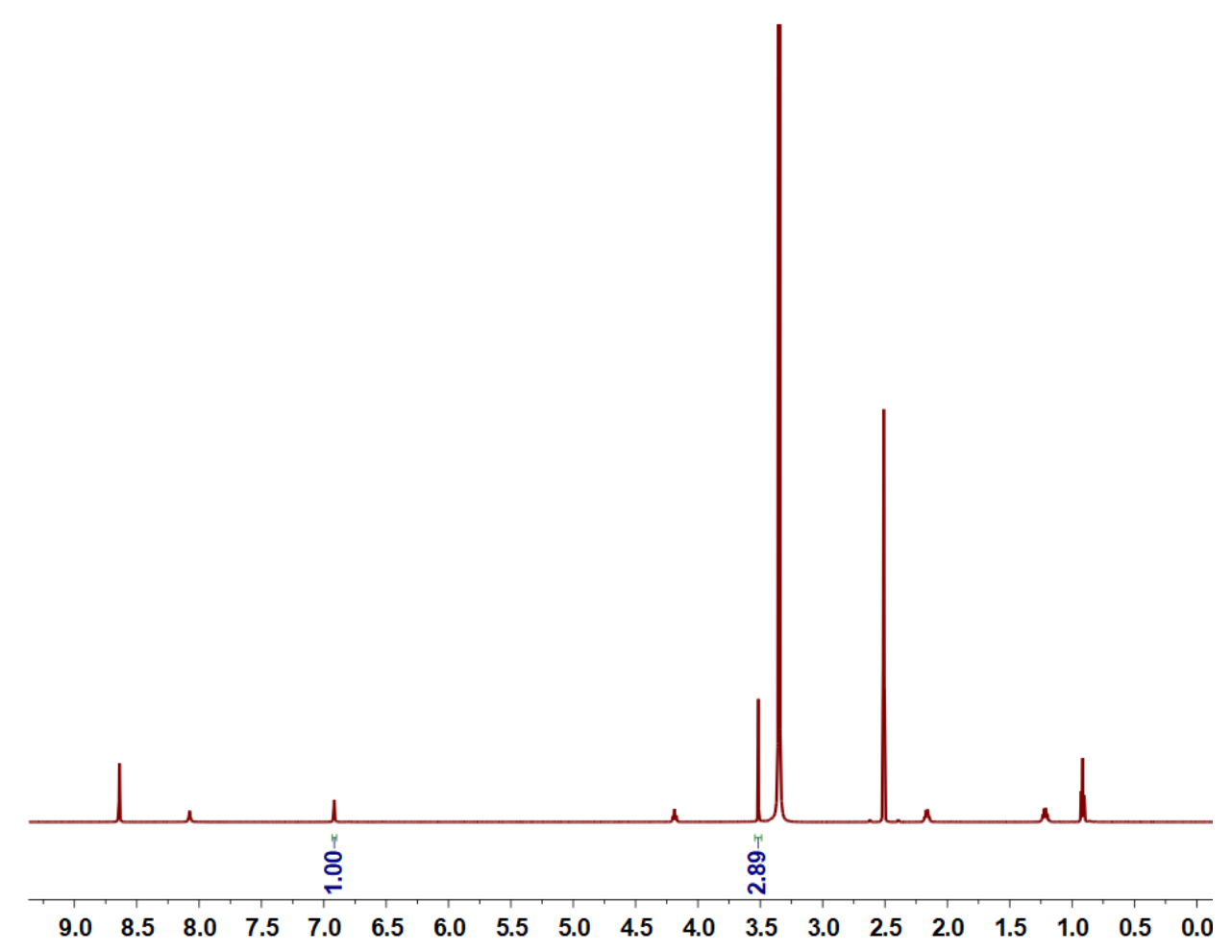

Figure S2. Partial ${ }^{1} \mathrm{H}$ NMR spectrum (600 MHz, DMSO- $d_{6}$, room temperature) of the coprecipitates formed by $\mathbf{P g C}_{3}$ and PEG2000.

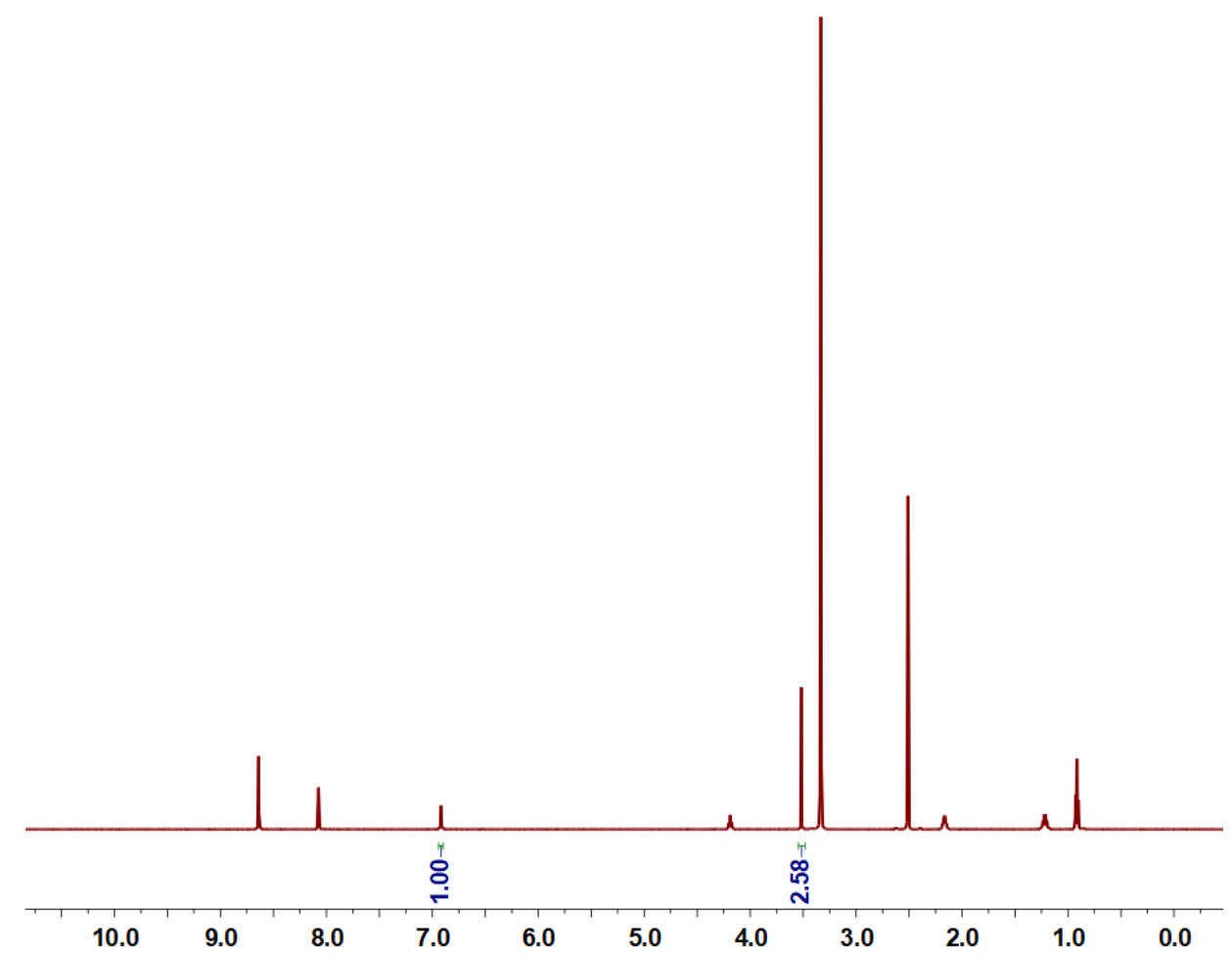

Figure S3. Partial ${ }^{1} \mathrm{H}$ NMR spectrum (600 MHz, DMSO- $d_{6}$, room temperature) of the coprecipitates formed by $\mathbf{P g C}_{3}$ and PEG4000. 


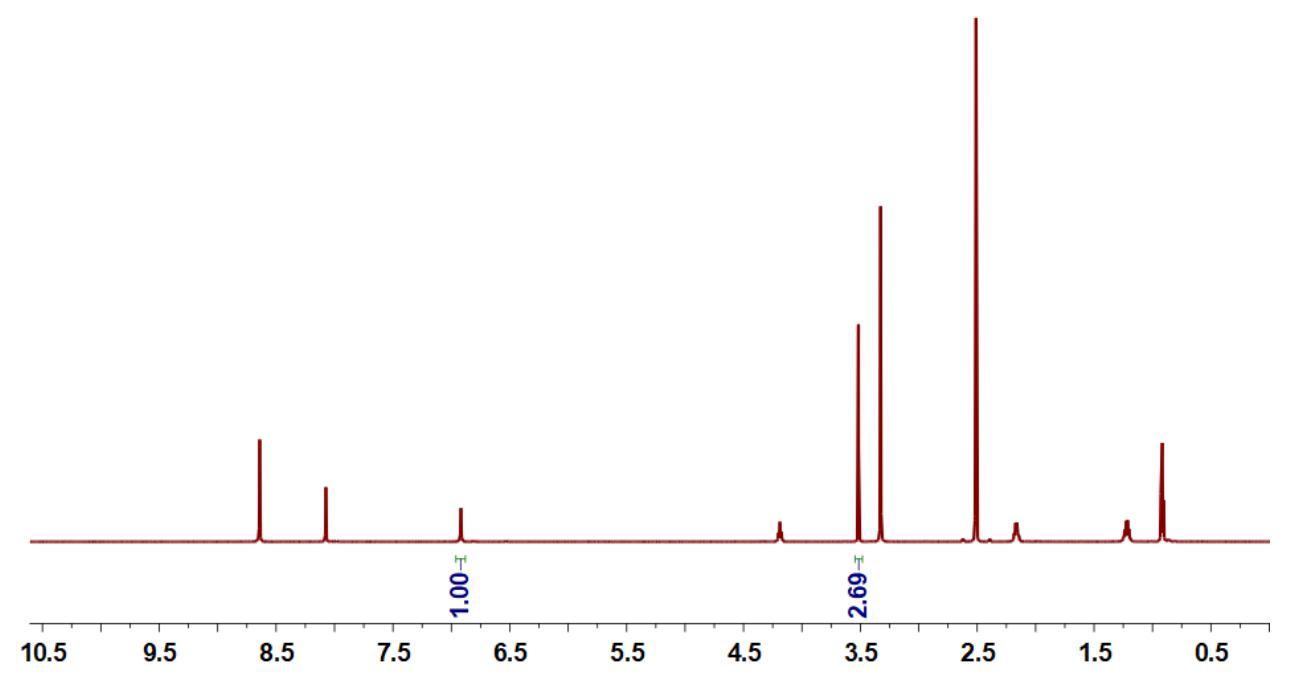

Figure S4. Partial ${ }^{1} \mathrm{H}$ NMR spectrum $\left(600 \mathrm{MHz}\right.$, DMSO- $d_{6}$, room temperature) of the coprecipitates formed by $\mathbf{P g C}_{3}$ and PEG6000.

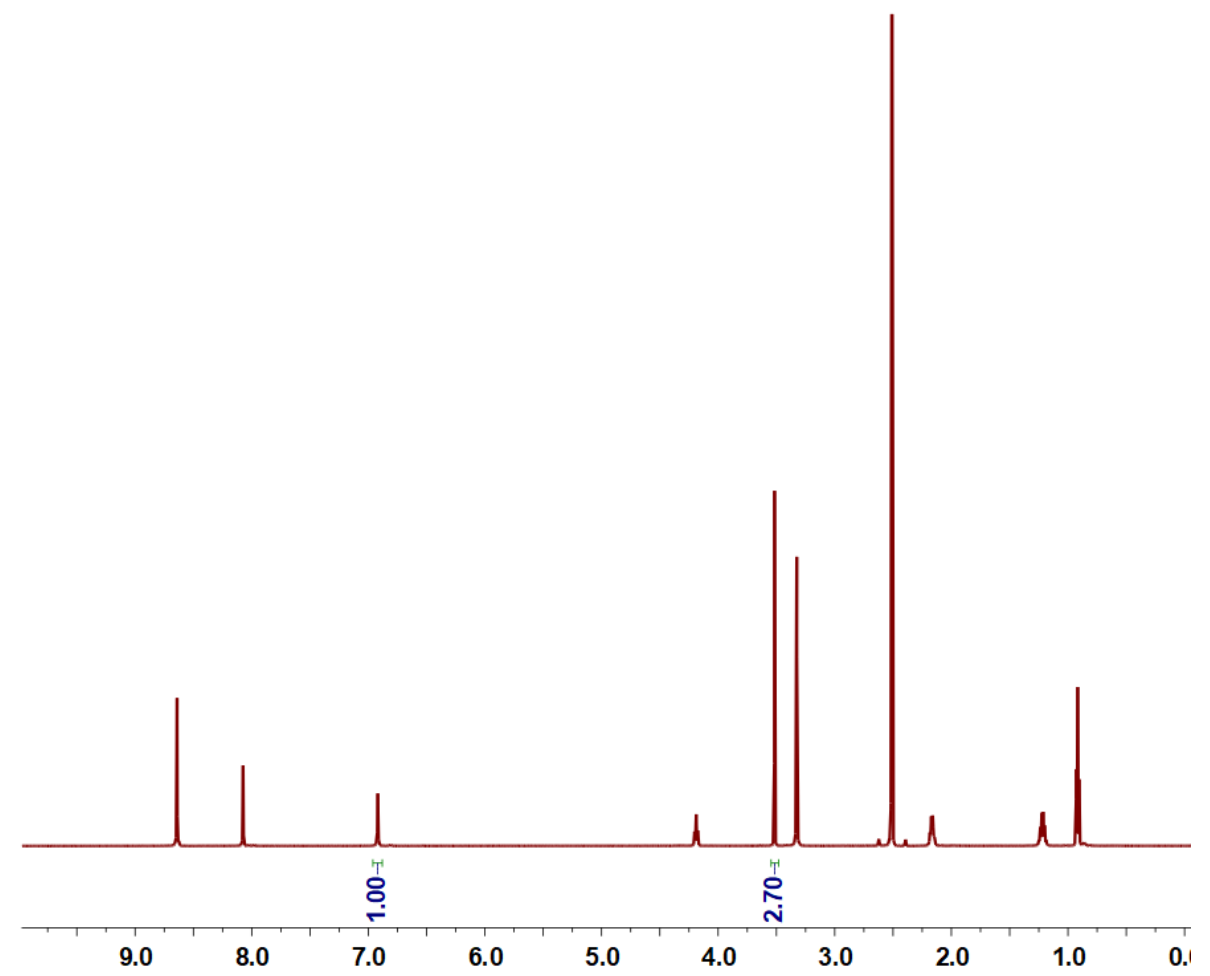

Figure S5. Partial ${ }^{1} \mathrm{H}$ NMR spectrum $\left(600 \mathrm{MHz}\right.$, DMSO- $d_{6}$, room temperature) of the coprecipitates formed by $\mathbf{P g C}_{3}$ and PEG8000. 


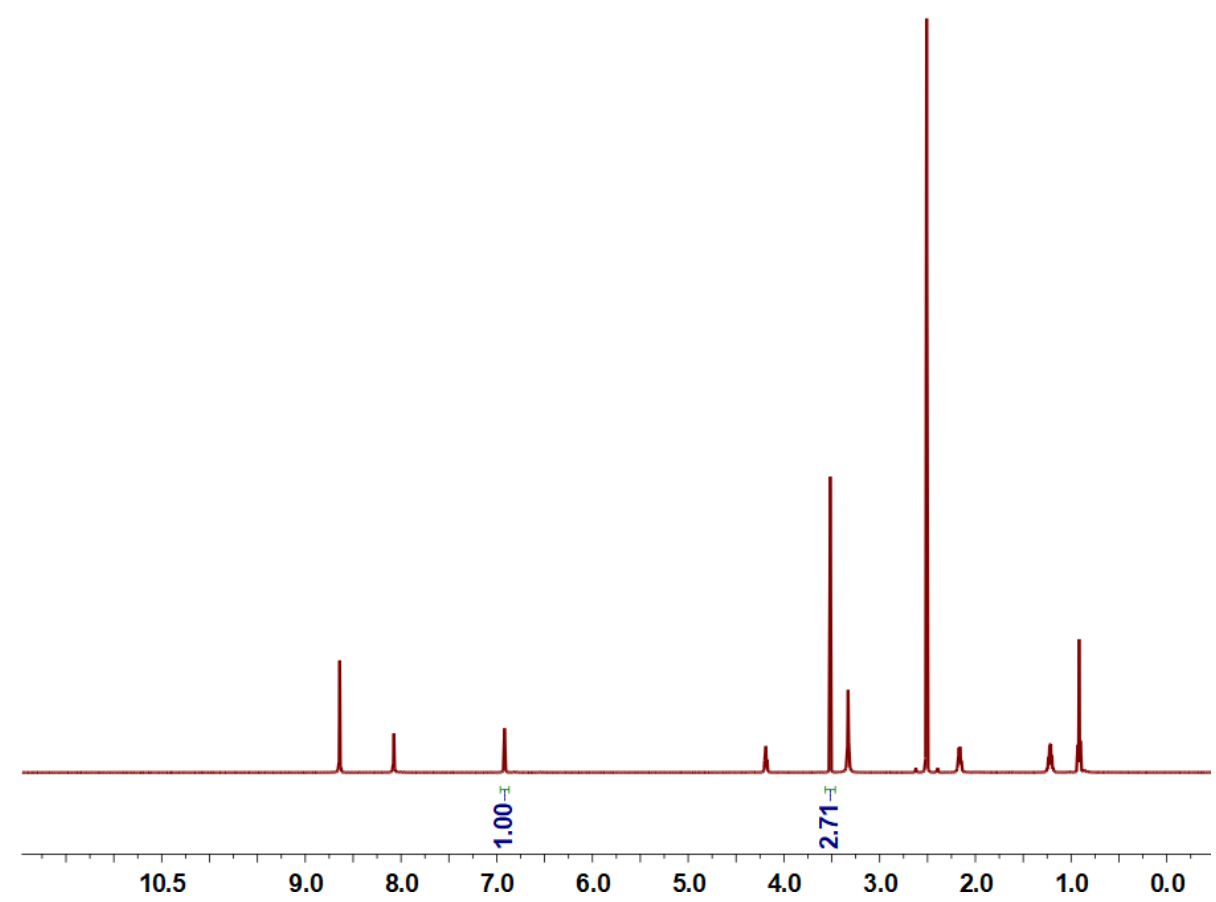

Figure S6. Partial ${ }^{1} \mathrm{H}$ NMR spectrum (600 MHz, DMSO- $d_{6}$, room temperature) of the coprecipitates formed by $\mathbf{P g C}_{3}$ and PEG10000.

4. Enlarged magic angle spinning $2 D$ heterocorrelated $N M R$ spectrum of $\boldsymbol{P g} C_{3} \supset P E G$

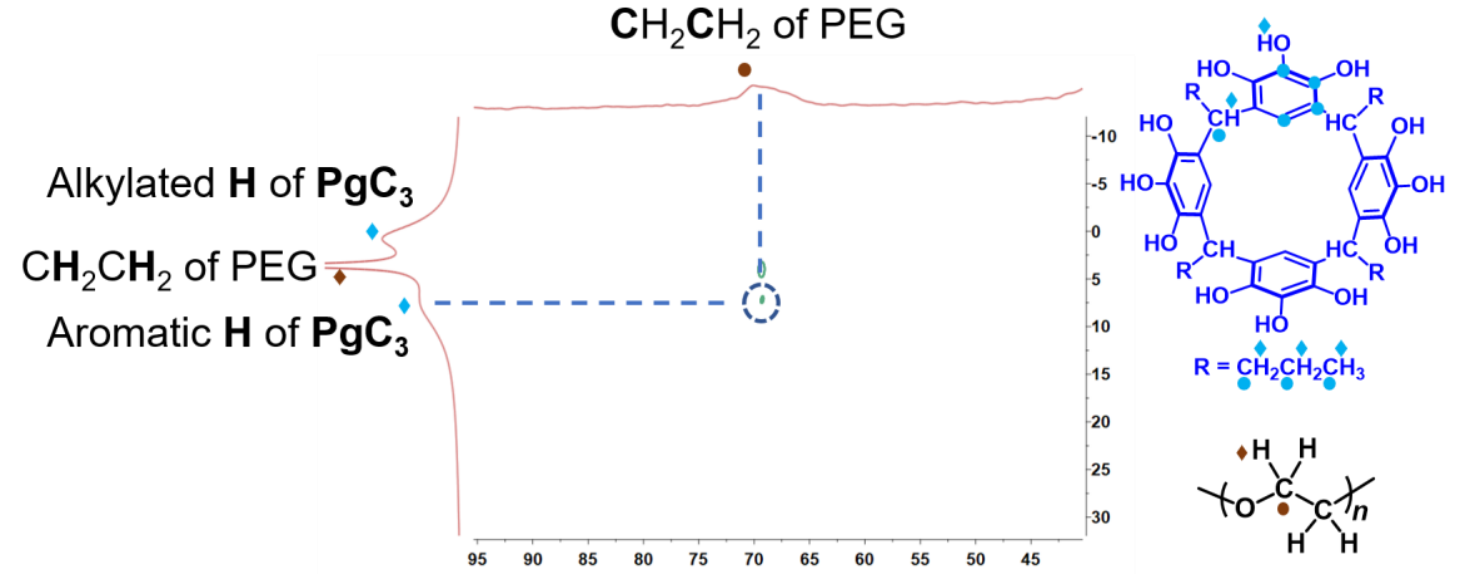

Figure S7. Enlarged magic angle spinning 2D heterocorrelated NMR spectrum of $\mathrm{PgC}_{3} \supset \mathrm{PEG}$.

5. FTIR spectra of $P g C_{3}, P E G$ and the complexes between $P g C_{3}$ and PEG with different molecular weights 


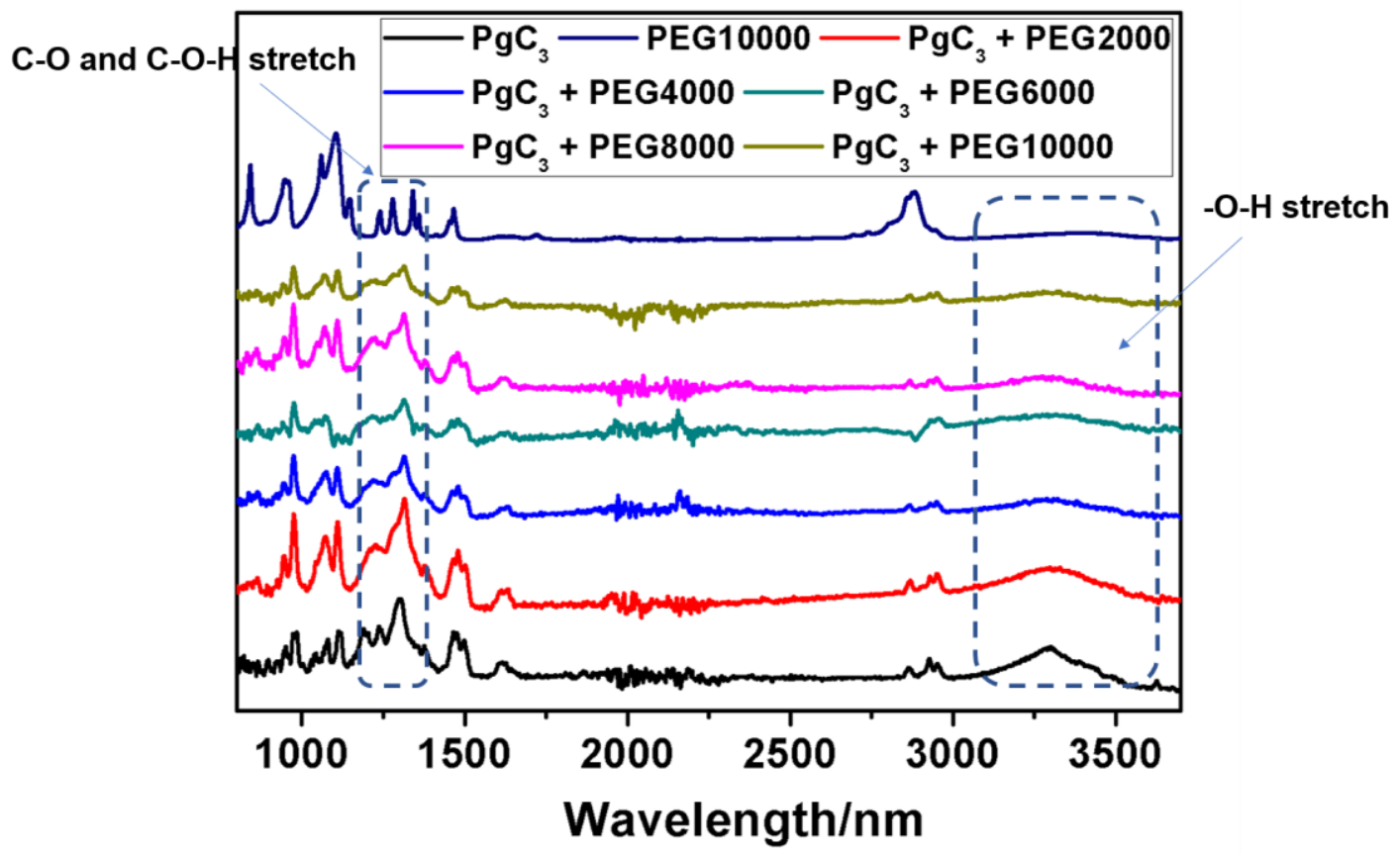

Figure S8. FTIR spectra of $\mathbf{P g C}_{3}$, PEG10000 and the complexes between $\mathbf{P g C}_{3}$ and PEG with different molecular weights.

Fourier-transform infrared spectroscopy (FTIR) of $\mathbf{P g C}_{\mathbf{3}}$, PEG10000 and the complexes between $\mathbf{P g C}_{3}$ and PEG with different molecular weights were performed (Figure S8). The peaks of $\mathbf{P g C}_{3} \supset \mathrm{PEG}$ at around $3300 \mathrm{~nm}$ belonged to $-\mathrm{OH}$ stretch could be observed and they were also broadened compared with that of individual $\mathbf{P g C}_{3}$, suggesting that strong hydrogen bonding interactions existed in the host-guest complex.

6. Stoichiometry determination for the complexation between $P g C_{3}$ and $P E G$ with different molecular weights in solution. 


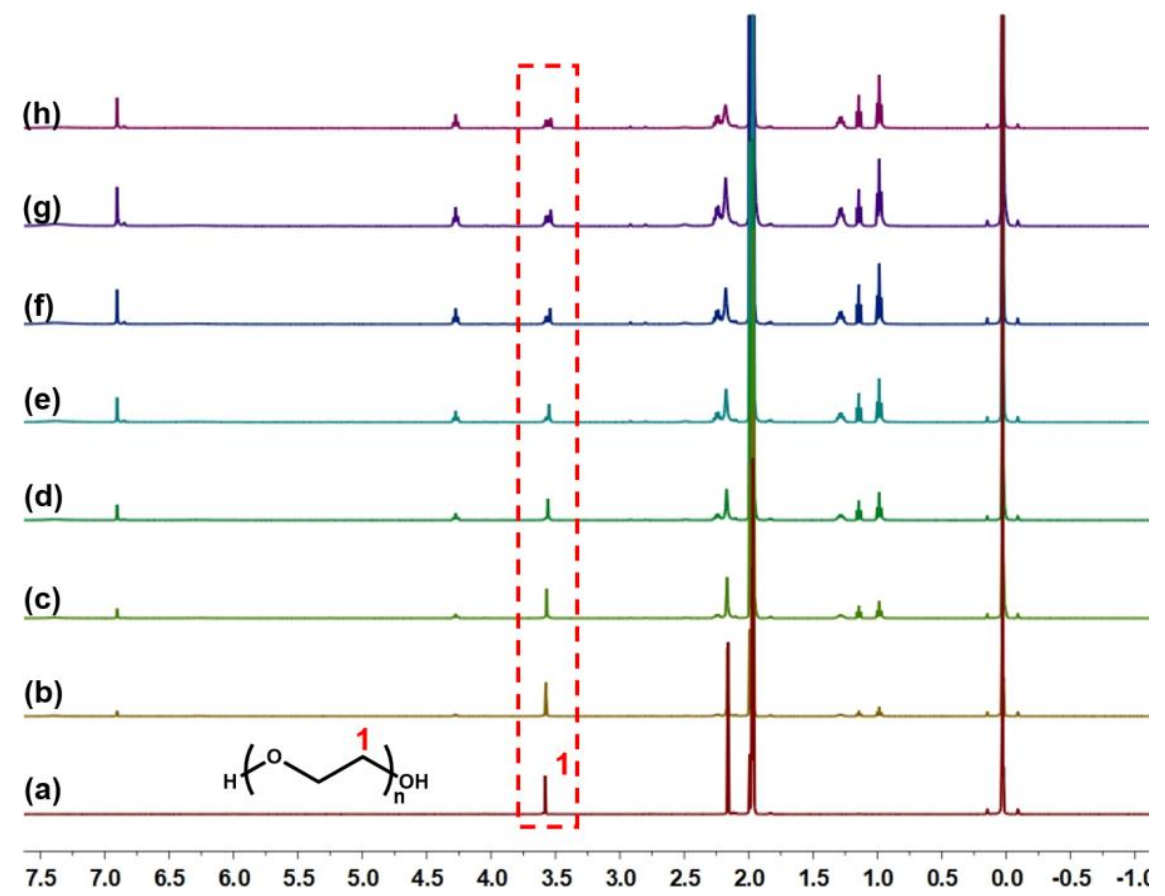

Figure S9. ${ }^{1} \mathrm{H}$ NMR spectra $\left(600 \mathrm{MHz}, \mathrm{CD}_{3} \mathrm{CN}\right.$, rt) of PEG2000 at a concentration of 0.100 $\mathrm{mM}$ with different concentrations of $\mathbf{P g C}_{3}$ : (a) $0.00 \mathrm{mM}$, (b) $0.91 \mathrm{mM}$, (c) $1.32 \mathrm{mM}$, (d) 3.00 mM, (e) $5.55 \mathrm{mM}$, (f) $8.18 \mathrm{mM}$, (g) $9.50 \mathrm{mM}$, (h) $10.45 \mathrm{mM}$.

(h)

(g)

(f)

(e)

(d)

(c)

(b)

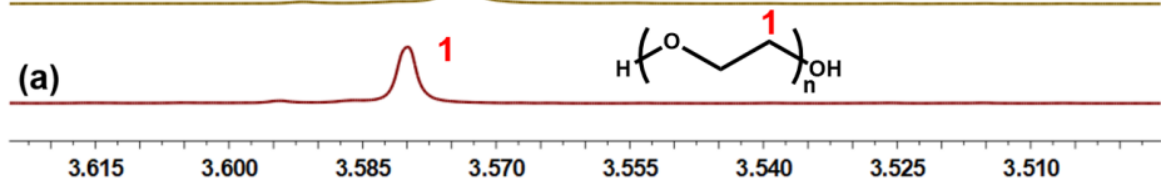

Figure S10. Partial ${ }^{1} \mathrm{H}$ NMR spectra $\left(600 \mathrm{MHz}, \mathrm{CD}_{3} \mathrm{CN}\right.$, rt) of PEG2000 at a concentration of $0.100 \mathrm{mM}$ with different concentrations of $\mathbf{P g C}_{3}$ : (a) $0.00 \mathrm{mM}$, (b) $0.91 \mathrm{mM}$, (c) $1.32 \mathrm{mM}$, (d) $3.00 \mathrm{mM}$, (e) $5.55 \mathrm{mM}$, (f) $8.18 \mathrm{mM}$, (g) $9.50 \mathrm{mM}$, (h) $10.45 \mathrm{mM}$. 


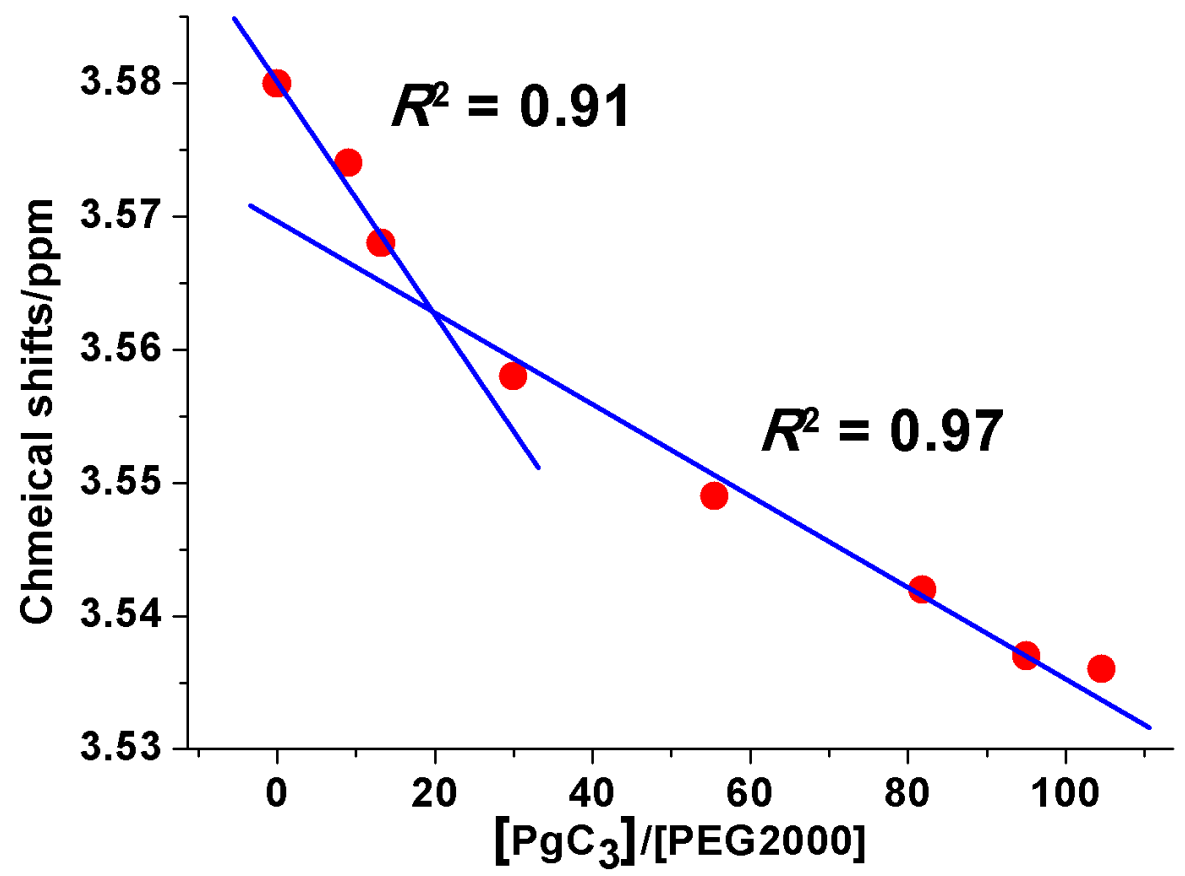

Figure S11. Molar ratio plot for the complexation between PEG2000 and $\mathbf{P g C}_{\mathbf{3}}$ in $\mathrm{CD}_{3} \mathrm{CN}$. The binding stoichiometry of $\left[\mathbf{P g C}_{\mathbf{3}}\right] /[\mathrm{PEG} 2000]$ was measured to be around 19:1.

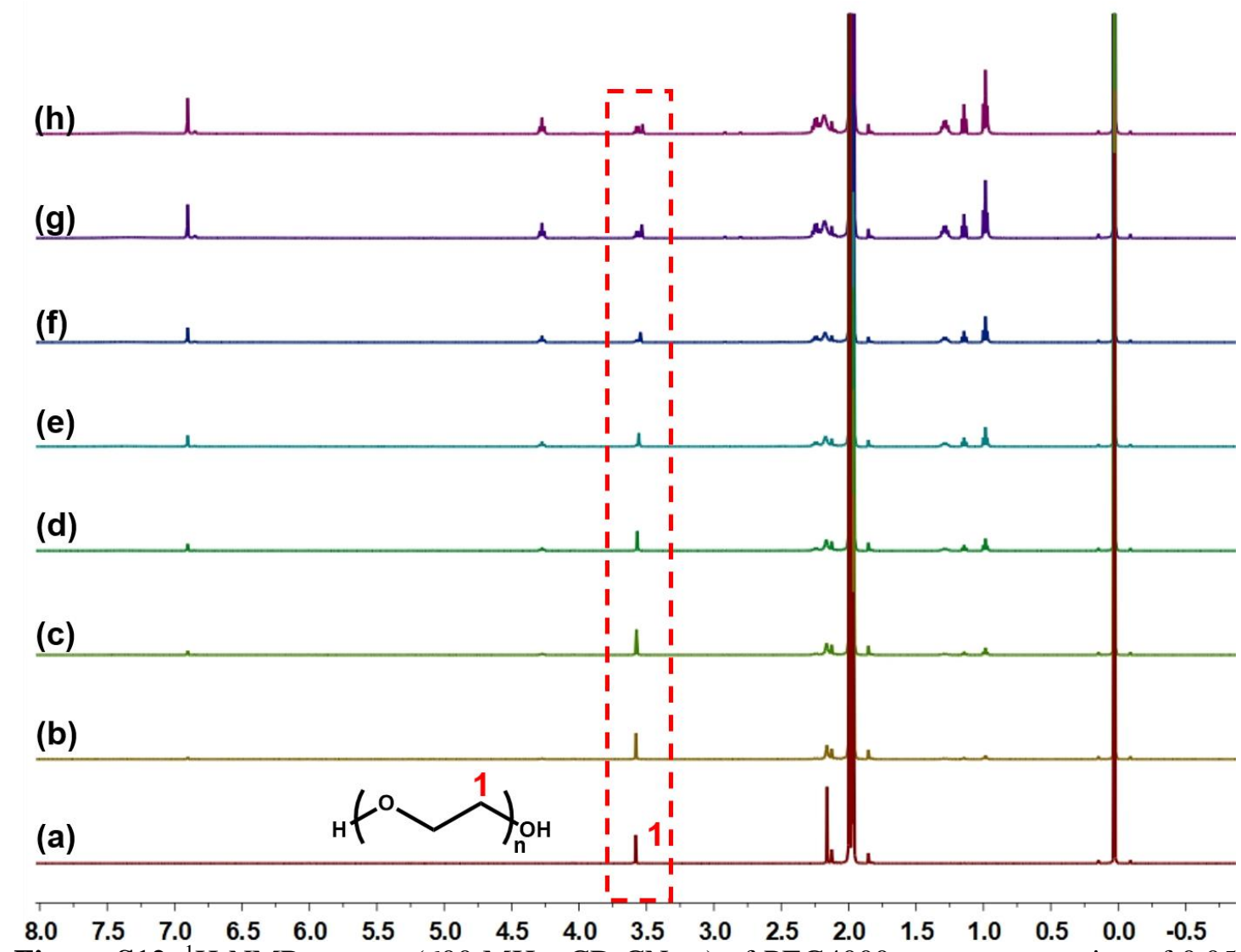

Figure S12. ${ }^{1} \mathrm{H}$ NMR spectra $\left(600 \mathrm{MHz}, \mathrm{CD}_{3} \mathrm{CN}\right.$, rt $)$ of PEG4000 at a concentration of 0.05 $\mathrm{mM}$ with different concentrations of $\mathbf{P g C}_{3}$ : (a) $0.00 \mathrm{mM}$, (b) $0.45 \mathrm{mM}$, (c) $0.91 \mathrm{mM}$, (d) 1.45 mM, (e) $4.27 \mathrm{mM}$, (f) $6.82 \mathrm{mM}$, (g) $9.63 \mathrm{mM}$, (h) $12.00 \mathrm{mM}$. 
(h)

(g)

(f)

(e)

(d)

(c)

(b)

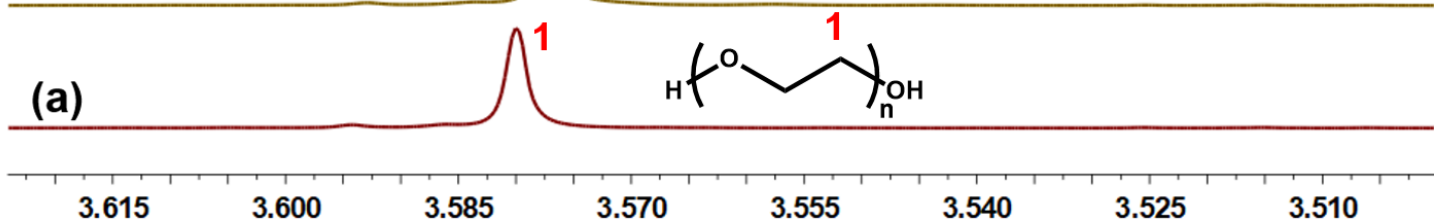

Figure S13. Partial ${ }^{1} \mathrm{H}$ NMR spectra $\left(600 \mathrm{MHz}, \mathrm{CD}_{3} \mathrm{CN}\right.$, rt) of PEG4000 at a concentration of $0.05 \mathrm{mM}$ with different concentrations of $\mathbf{P g C}_{3}$ : (a) $0.00 \mathrm{mM}$, (b) $0.45 \mathrm{mM}$, (c) $0.91 \mathrm{mM}$, (d) $1.45 \mathrm{mM}$, (e) $4.27 \mathrm{mM}$, (f) $6.82 \mathrm{mM}$, (g) $9.63 \mathrm{mM}$, (h) $12.00 \mathrm{mM}$.

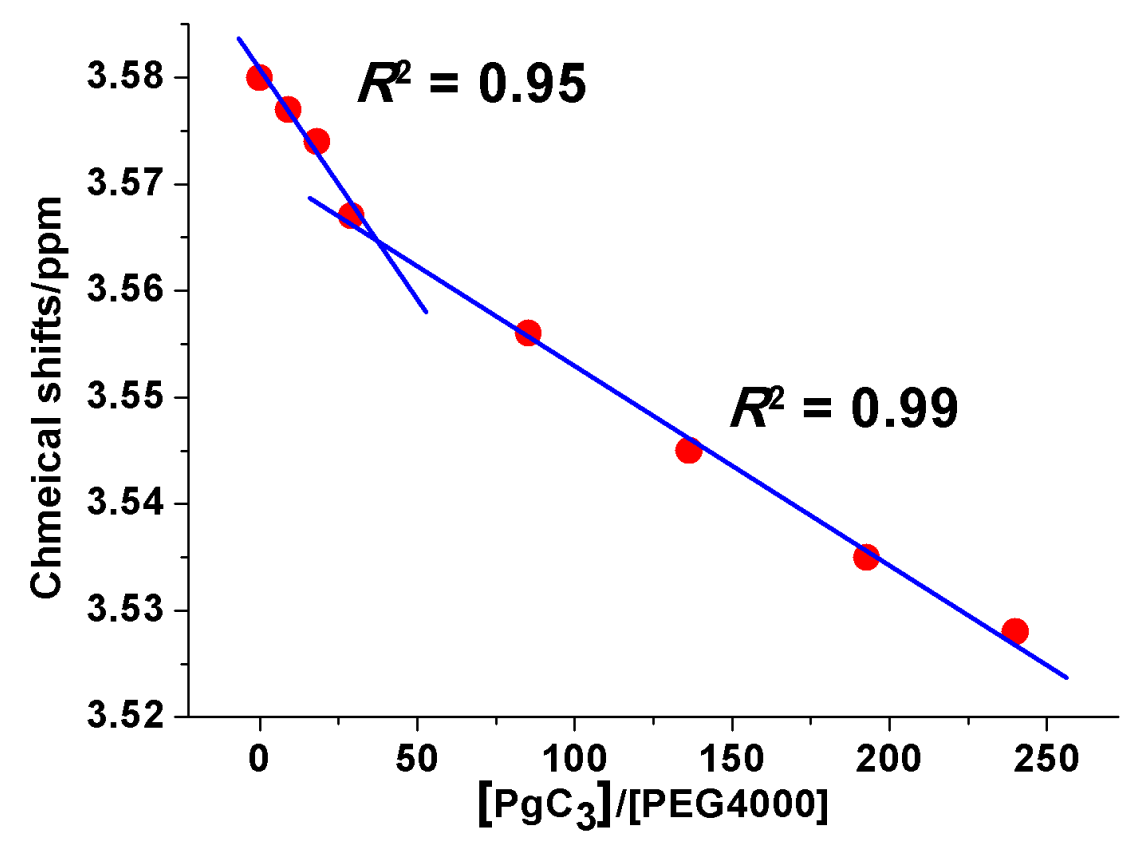

Figure S14. Molar ratio plot for the complexation between PEG4000 and $\mathbf{P g C}_{3}$ in $\mathrm{CD}_{3} \mathrm{CN}$.

The binding stoichiometry of $\left[\mathbf{P g C}_{3}\right] /[\mathrm{PEG} 4000]$ was measured to be around 37:1. 


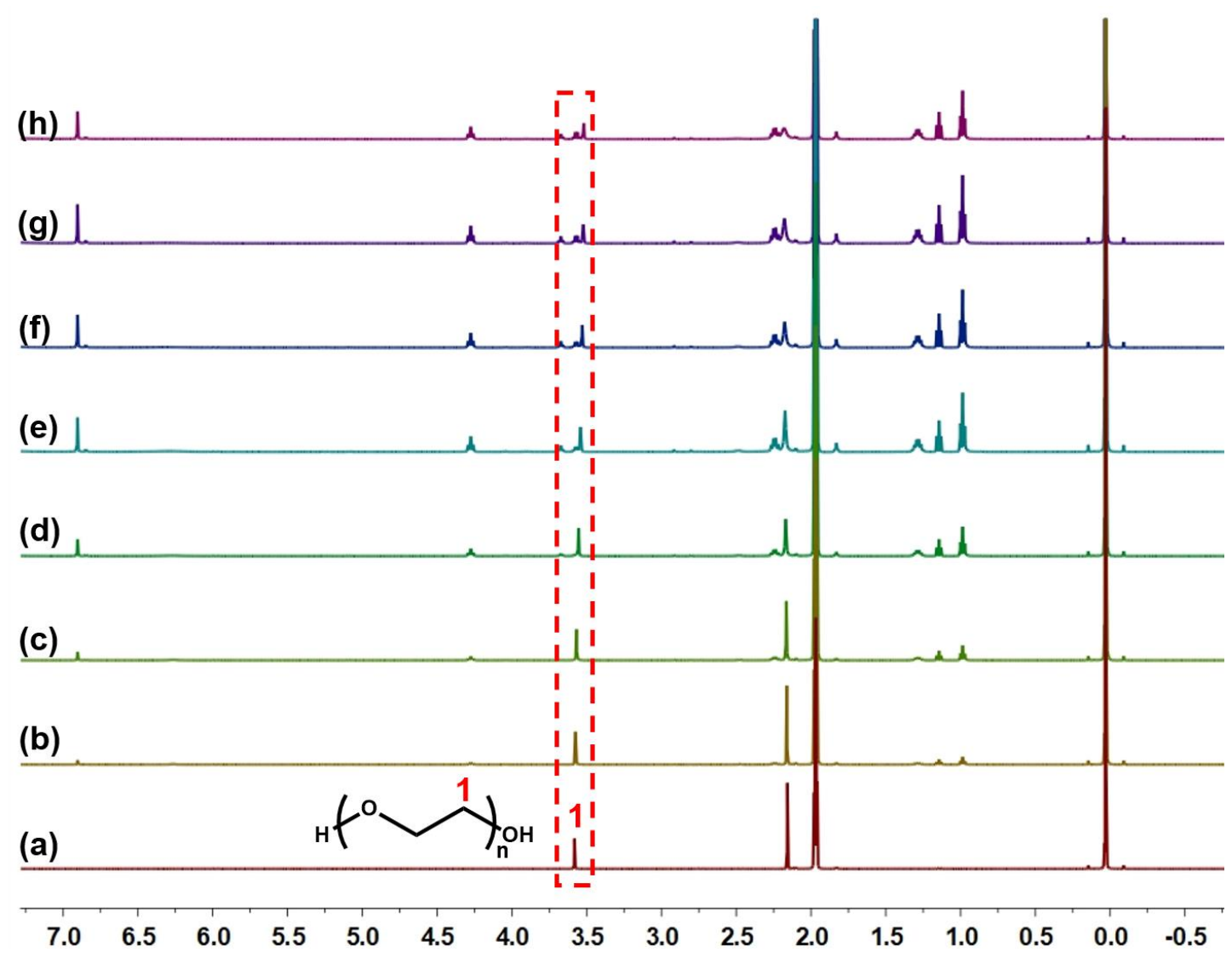

Figure S15. ${ }^{1} \mathrm{H}$ NMR spectra $\left(600 \mathrm{MHz}, \mathrm{CD}_{3} \mathrm{CN}\right.$, rt) of PEG6000 at a concentration of 0.033 $\mathrm{mM}$ with different concentrations of $\mathbf{P g C}_{3}$ : (a) $0.00 \mathrm{mM}$, (b) $0.77 \mathrm{mM}$, (c) $1.14 \mathrm{mM}$, (d) 2.18 mM, (e) $4.18 \mathrm{mM}$, (f) $5.54 \mathrm{mM}$, (g) $6.68 \mathrm{mM}$, (h) $7.13 \mathrm{mM}$. 
(h)

(g)

(f)

(e)

(d)

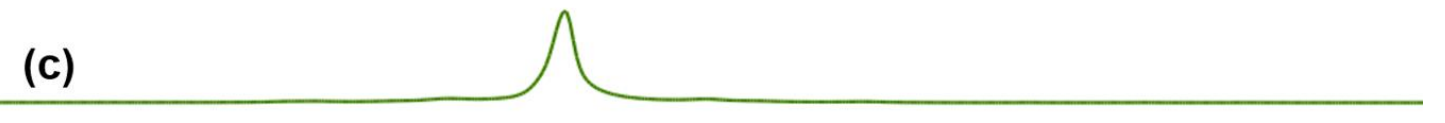

(b)

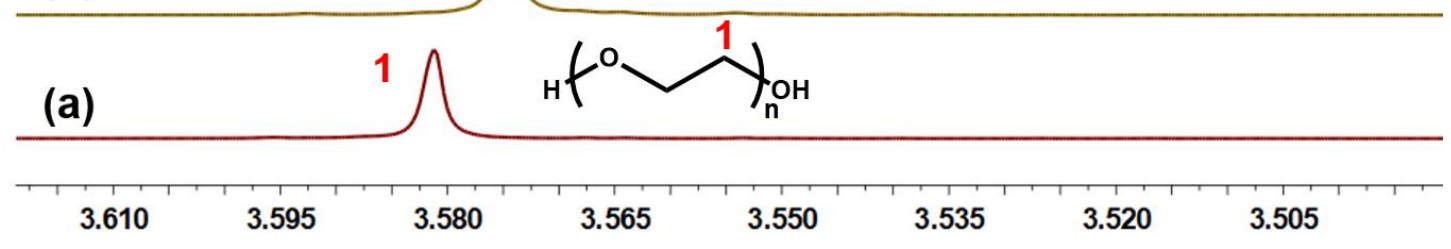

Figure S16. Partial ${ }^{1} \mathrm{H}$ NMR spectra $\left(600 \mathrm{MHz}, \mathrm{CD}_{3} \mathrm{CN}\right.$, rt) of PEG6000 at a concentration of $0.033 \mathrm{mM}$ with different concentrations of $\mathbf{P g C}_{3}$ : (a) $0.00 \mathrm{mM}$, (b) $0.77 \mathrm{mM}$, (c) $1.14 \mathrm{mM}$, (d) $2.18 \mathrm{mM}$, (e) $4.18 \mathrm{mM}$, (f) $5.54 \mathrm{mM}$, (g) $6.68 \mathrm{mM}$, (h) $7.13 \mathrm{mM}$.

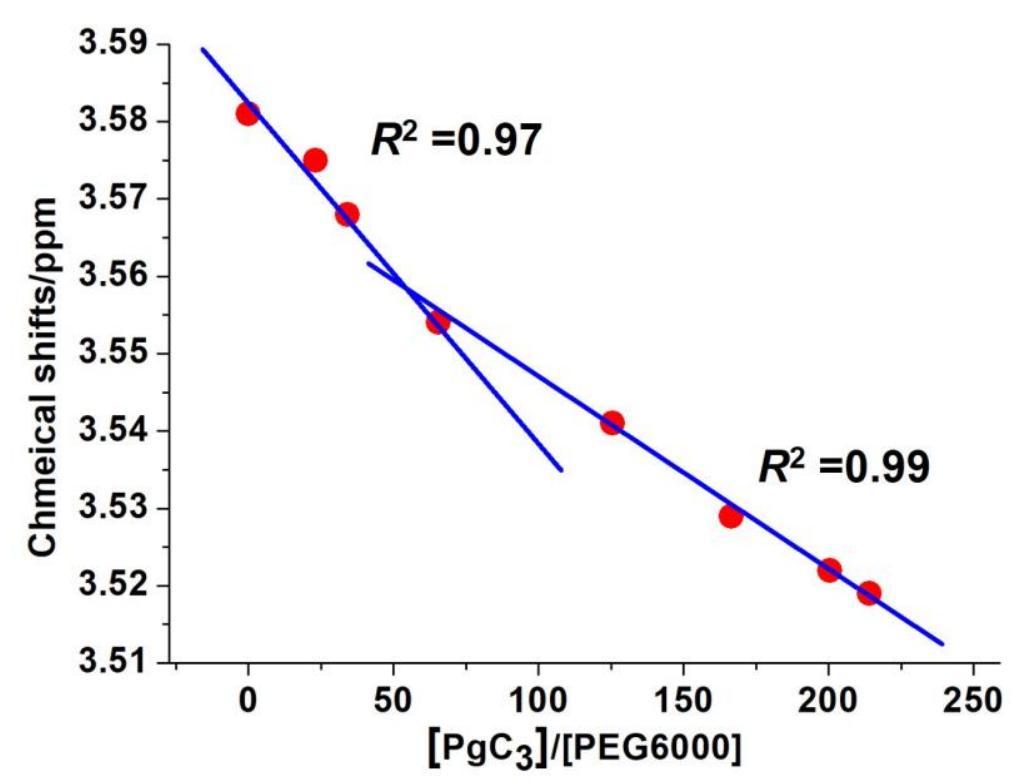

Figure S17. Molar ratio plot for the complexation between PEG6000 and $\mathbf{P g C}_{3}$ in $\mathrm{CD}_{3} \mathrm{CN}$.

The binding stoichiometry of $\left[\mathbf{P g C}_{3}\right] /[\mathrm{PEG} 6000]$ was measured to be around 55:1. 


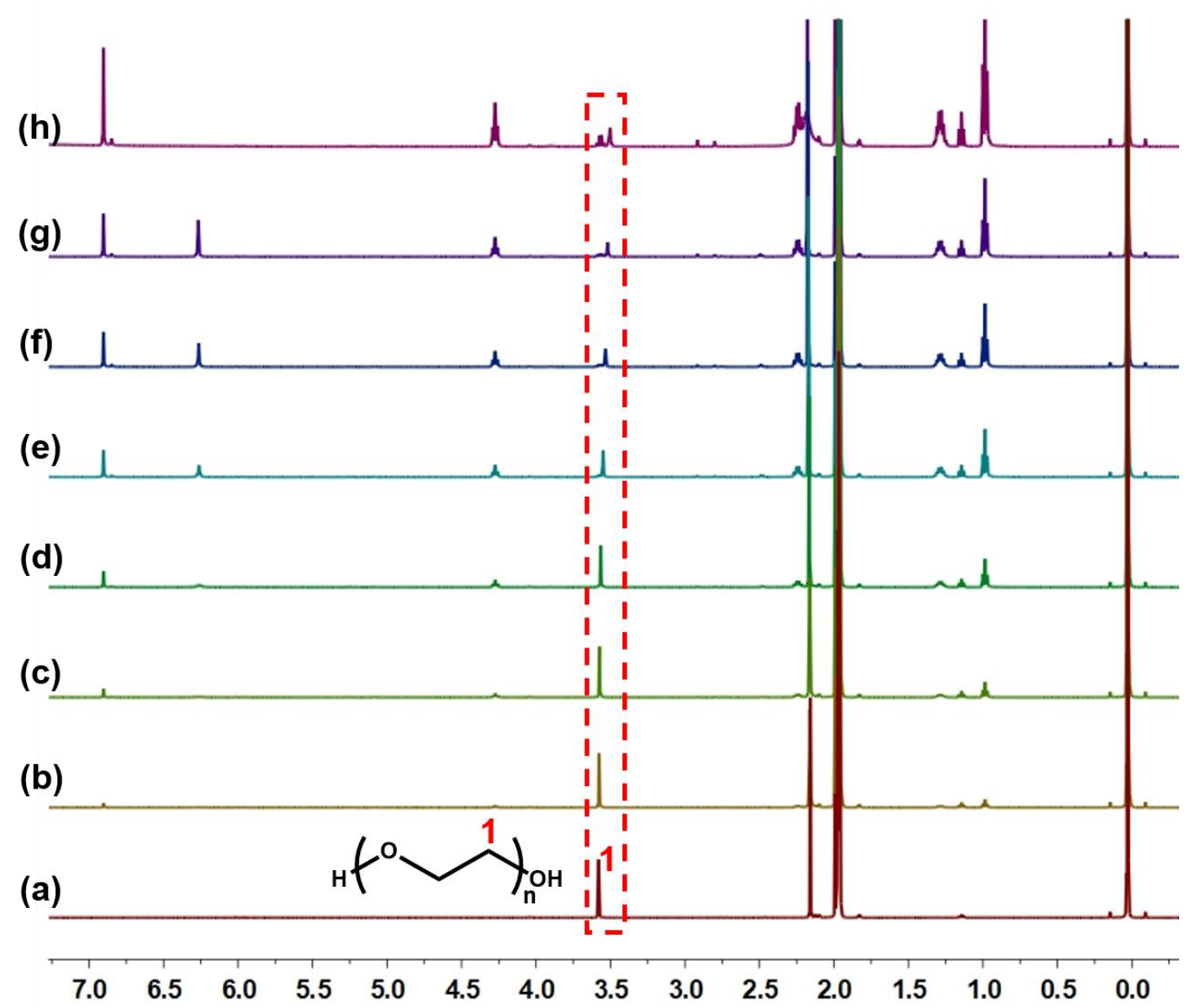

Figure S18. ${ }^{1} \mathrm{H}$ NMR spectra $\left(600 \mathrm{MHz}, \mathrm{CD}_{3} \mathrm{CN}\right.$, rt) of PEG8000 at a concentration of 0.025 $\mathrm{mM}$ with different concentrations of $\mathbf{P g C}_{3}$ : (a) $0.00 \mathrm{mM}$, (b) $0.455 \mathrm{mM}$, (c) $0.862 \mathrm{mM}$, (d) $1.725 \mathrm{mM}$, (e) $4.09 \mathrm{mM}$, (f) $6.182 \mathrm{mM}$, (g) $7.772 \mathrm{mM}$, (h) $9.59 \mathrm{mM}$. 
(h)

(g)

(f)

(e)

(d)

(c)

(b)

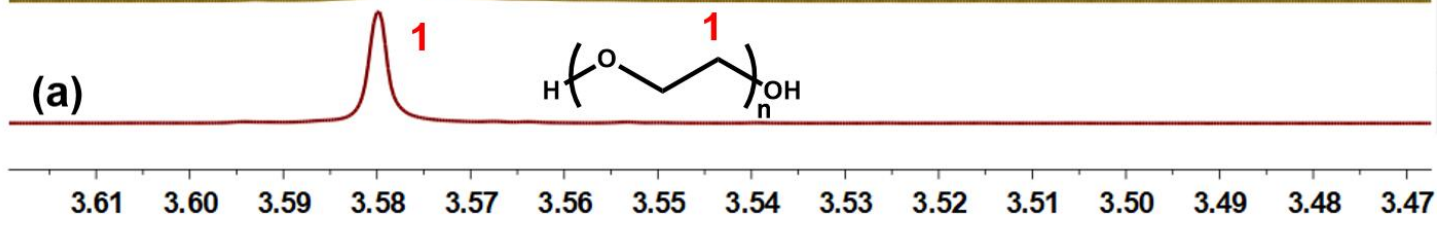

Figure S19. Partial ${ }^{1} \mathrm{H}$ NMR spectra $\left(600 \mathrm{MHz}, \mathrm{CD}_{3} \mathrm{CN}\right.$, rt) of PEG8000 at a concentration of $0.025 \mathrm{mM}$ with different concentrations of $\mathbf{P g C}_{3}$ : (a) $0.00 \mathrm{mM}$, (b) $0.455 \mathrm{mM}$, (c) $0.862 \mathrm{mM}$, (d) $1.725 \mathrm{mM}$, (e) $4.09 \mathrm{mM}$, (f) $6.182 \mathrm{mM}$, (g) $7.772 \mathrm{mM}$, (h) $9.59 \mathrm{mM}$.

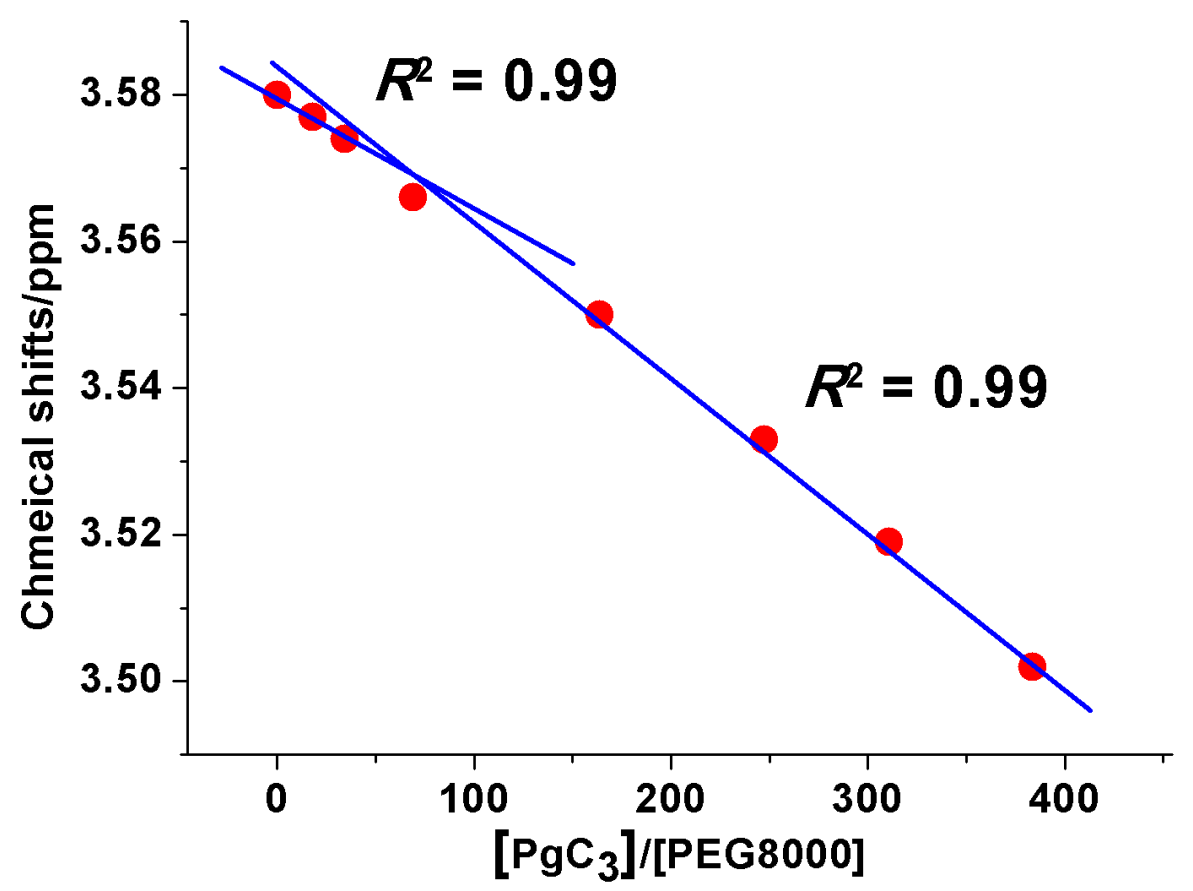

Figure S20. Molar ratio plot for the complexation between PEG8000 and $\mathbf{P g C}_{3}$ in $\mathrm{CD}_{3} \mathrm{CN}$, indicating a 67:1 binding stoichiometry of $\left[\mathrm{PgC}_{3}\right] /[\mathrm{PEG} 8000]$. 


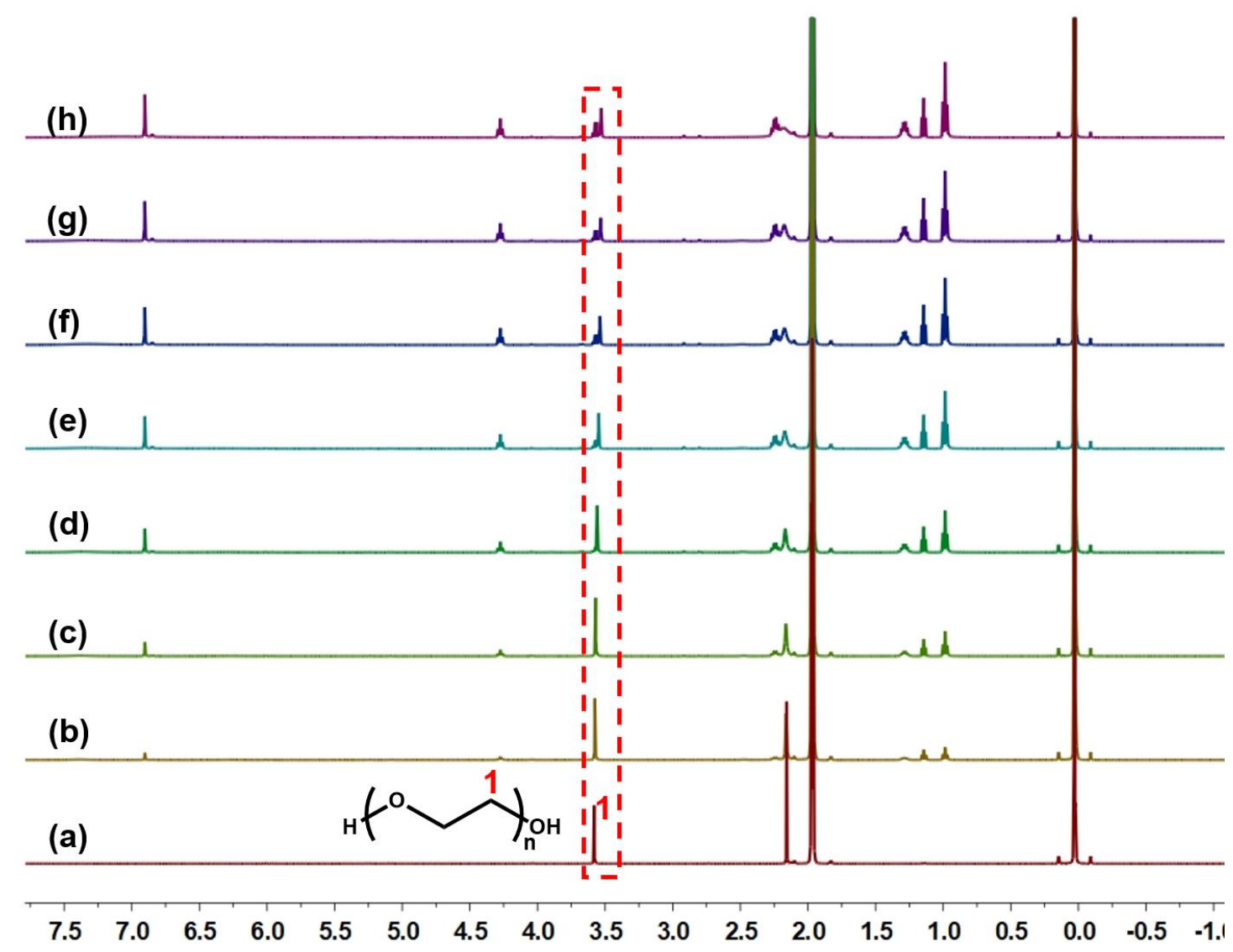

Figure S21. ${ }^{1} \mathrm{H}$ NMR spectra $\left(600 \mathrm{MHz}, \mathrm{CD}_{3} \mathrm{CN}\right.$, rt) of PEG10000 at a concentration of 0.02 $\mathrm{mM}$ with different concentrations of $\mathbf{P g C}_{3}$ : (a) $0.00 \mathrm{mM}$, (b) $0.636 \mathrm{mM}$, (c) $1.18 \mathrm{mM}$, (d) $2.636 \mathrm{mM}$, (e) $4.228 \mathrm{mM}$, (f) $5.864 \mathrm{mM}$, (g) $6.59 \mathrm{mM}$, (h) $7.45 \mathrm{mM}$. 
(h)

(g)

(f)

(e)

(d)

(c)

(b)

(a)

Figure S22. Partial ${ }^{1} \mathrm{H}$ NMR spectra $\left(600 \mathrm{MHz}, \mathrm{CD}_{3} \mathrm{CN}\right.$, rt) of PEG10000 at a concentration of $0.02 \mathrm{mM}$ with different concentrations of $\mathbf{P g C}_{3}$ : (a) $0.00 \mathrm{mM}$, (b) $0.636 \mathrm{mM}$, (c) $1.18 \mathrm{mM}$, (d) $2.636 \mathrm{mM}$, (e) $4.228 \mathrm{mM}$, (f) $5.864 \mathrm{mM}$, (g) $6.59 \mathrm{mM}$, (h) $7.45 \mathrm{mM}$.

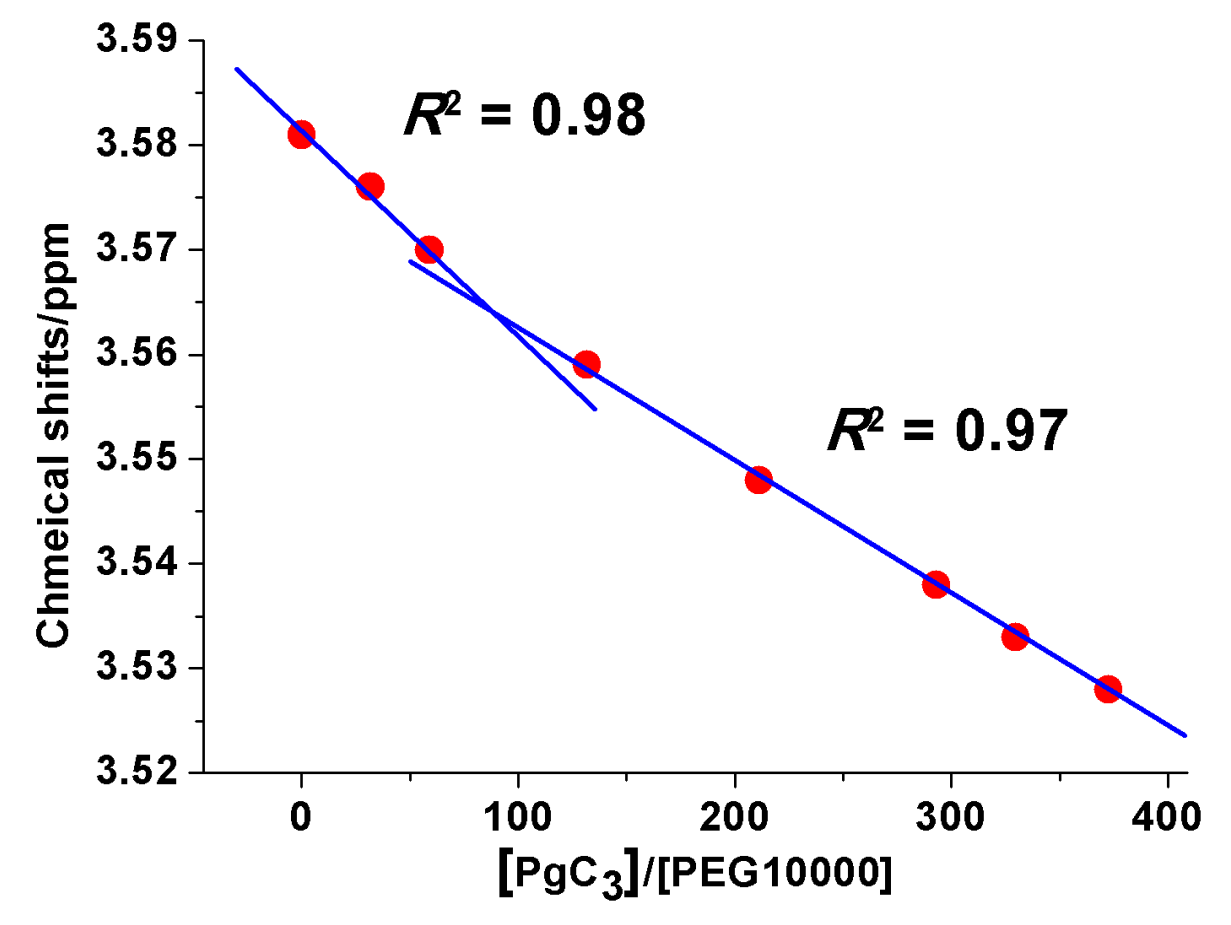


Figure S23. Molar ratio plot for the complexation between PEG10000 and $\mathbf{P g C}_{\mathbf{3}}$ in a solvent of $\mathrm{CD}_{3} \mathrm{CN}$. The binding stoichiometry of $\left[\mathrm{PgC}_{3}\right] /[\mathrm{PEG} 10000]$ was measured to be around $85: 1$.

7. Association constant determination for the complexation between $\mathbf{P g C}_{3}$ and diethylene glycol

Because the stoichiometries between $\mathrm{PgC}_{3}$ and PEG with different molecular weights were too high, the association constants $\left(K_{1}, K_{2}, K_{3} \ldots\right)$ were not only computationally difficult to be calculated but also the increased number of unknown parameters $\left(K_{1}\right.$, $K_{2}, K_{3} \ldots$ ) makes it difficult to get any meaningful results from the fitting process. ${ }^{[\mathrm{S} 7]}$ According to the stoichiometry measured before, one $\mathbf{P g C}_{3}$ molecule tended to associate with about two $-\mathrm{CH}_{2} \mathrm{CH}_{2} \mathrm{O}$ - repeating units. Thus, model compound diethylene glycol (DEG) was used to investigate the binding ability between $\mathbf{P g C}_{\mathbf{3}}$ and PEG. ${ }^{1} \mathrm{H}$ NMR titration was done with solutions which had a constant concentration of $\mathbf{P g C}_{3}(1.00 \mathrm{mM})$ and varying concentrations of DEG. By a non-linear curve-fitting method, the association constant between guest DEG and host $\mathbf{P g C}_{3}$ was calculated. The non-linear curve-fitting was based on the equation: ${ }^{[\mathrm{S} 8]}$ $\Delta \delta=\left(\Delta \delta_{\infty} /[\mathrm{H}]_{0}\right)\left(0.5[\mathrm{G}]_{0}+0.5\left([\mathrm{H}]_{0}+1 / K_{\mathrm{a}}\right)-\left(0.5\left([\mathrm{G}]_{0}^{2}+\left(2[\mathrm{G}]_{0}\left(1 / K_{\mathrm{a}}-[\mathrm{H}]_{0}\right)\right)+\left(1 / K_{\mathrm{a}}\right.\right.\right.\right.$ $\left.\left.\left.\left.+[\mathrm{H}]_{0}\right)^{2}\right)^{0.5}\right)\right) \quad($ Eq. S1)

where $\Delta \delta$ is the chemical shift change of $\mathrm{H}_{\mathrm{c}}$ on $\mathbf{P g C}_{3}$ at $[\mathrm{G}]_{0}, \Delta \delta_{\infty}$ is the chemical shift change of protons $\mathrm{H}_{\mathrm{c}}$ on $\mathbf{P g C}_{3}$ when the host is completely complexed, $[\mathrm{H}]_{0}$ is the fixed initial concentration of $\mathbf{P g C}_{3}$, and $[\mathrm{G}]_{0}$ is the varying concentration of DEG. 


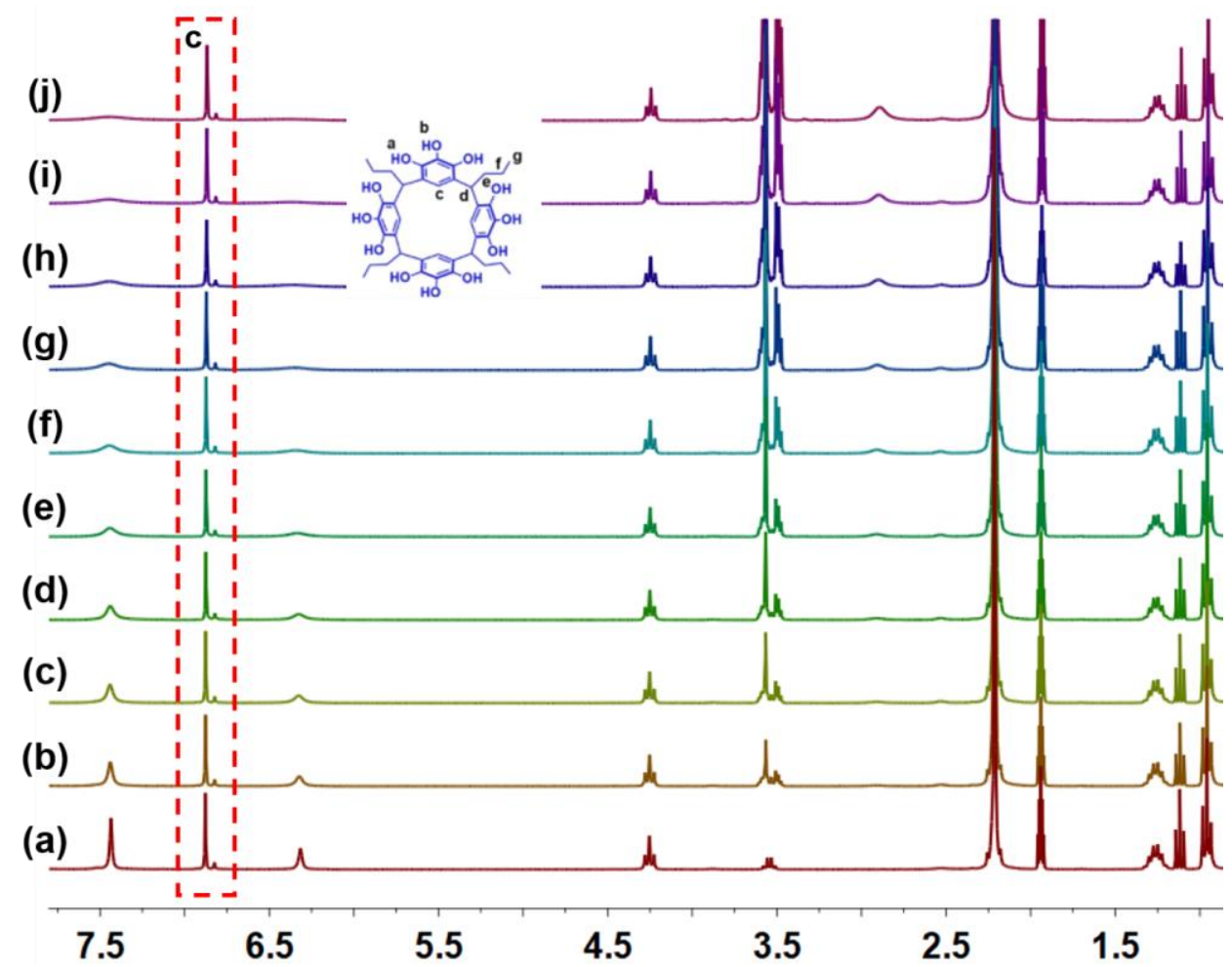

Figure S24. ${ }^{1} \mathrm{H}$ NMR spectra $\left(600 \mathrm{MHz}, \mathrm{CD}_{3} \mathrm{CN}\right.$, rt) of $\mathbf{P g C}_{3}$ at a concentration of $1.00 \mathrm{mM}$ with different concentrations of diethylene glycol: (a) $0.00 \mathrm{mM}$, (b) $0.40 \mathrm{mM}$, (c) $0.64 \mathrm{mM}$, (d) $0.78 \mathrm{mM}$, (e) $1.11 \mathrm{mM}$, (f) $1.42 \mathrm{mM}$, (g) $1.90 \mathrm{mM}$, (h) $2.53 \mathrm{mM}$, (i) $3.31 \mathrm{mM}$, (j) 3.80 $\mathrm{mM}$. 


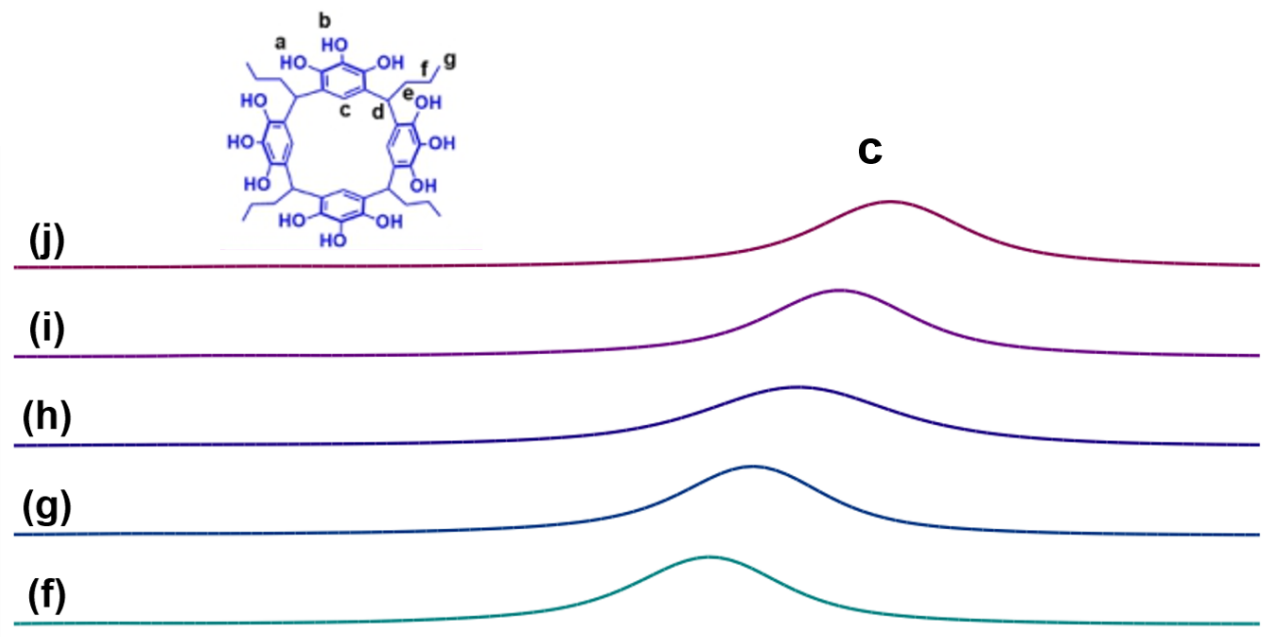

(e)
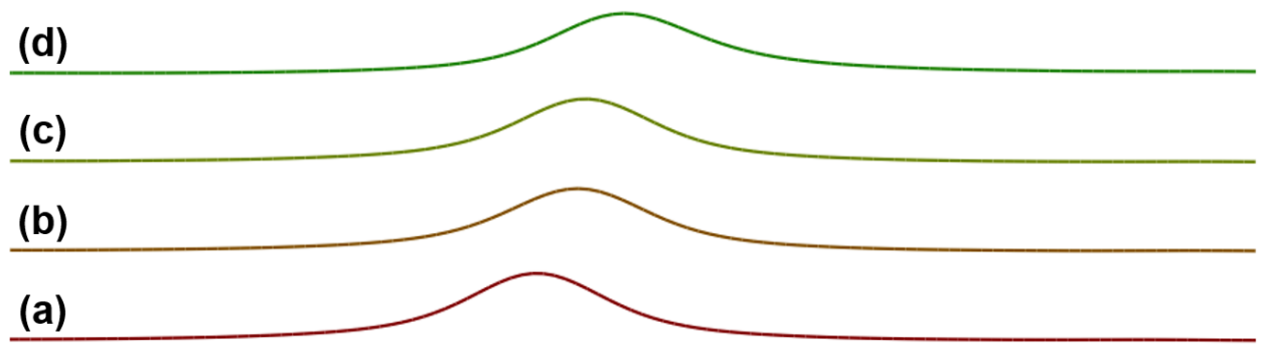

\section{$\begin{array}{llll}6.888 & 6.880 & 6.872 & 6.864\end{array}$}

Figure S25. Enlarged ${ }^{1} \mathrm{H}$ NMR spectra of protons $\mathrm{H}_{\mathrm{c}}$ of $1.00 \mathrm{mM} \mathrm{PgC}_{\mathbf{3}}$ with different concentrations of diethylene glycol: (a) $0.00 \mathrm{mM}$, (b) $0.40 \mathrm{mM}$, (c) $0.64 \mathrm{mM}$, (d) $0.78 \mathrm{mM}$, (e) $1.11 \mathrm{mM}$, (f) $1.42 \mathrm{mM}$, (g) $1.90 \mathrm{mM}$, (h) $2.53 \mathrm{mM}$, (i) $3.31 \mathrm{mM}$, (j) $3.80 \mathrm{mM}$.

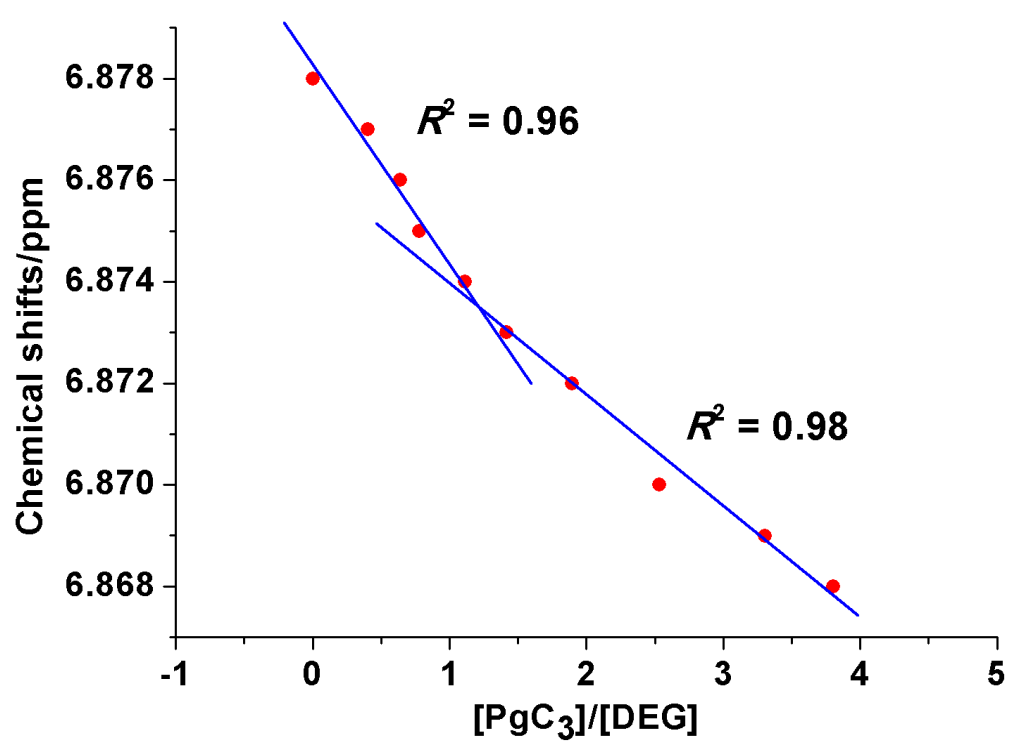

Figure S26. Molar ratio plot for the complexation between DEG and $\mathbf{P g C}_{3}$ in $\mathrm{CD}_{3} \mathrm{CN}$. The complexation stoichiometry was measured to be $1: 1$. 


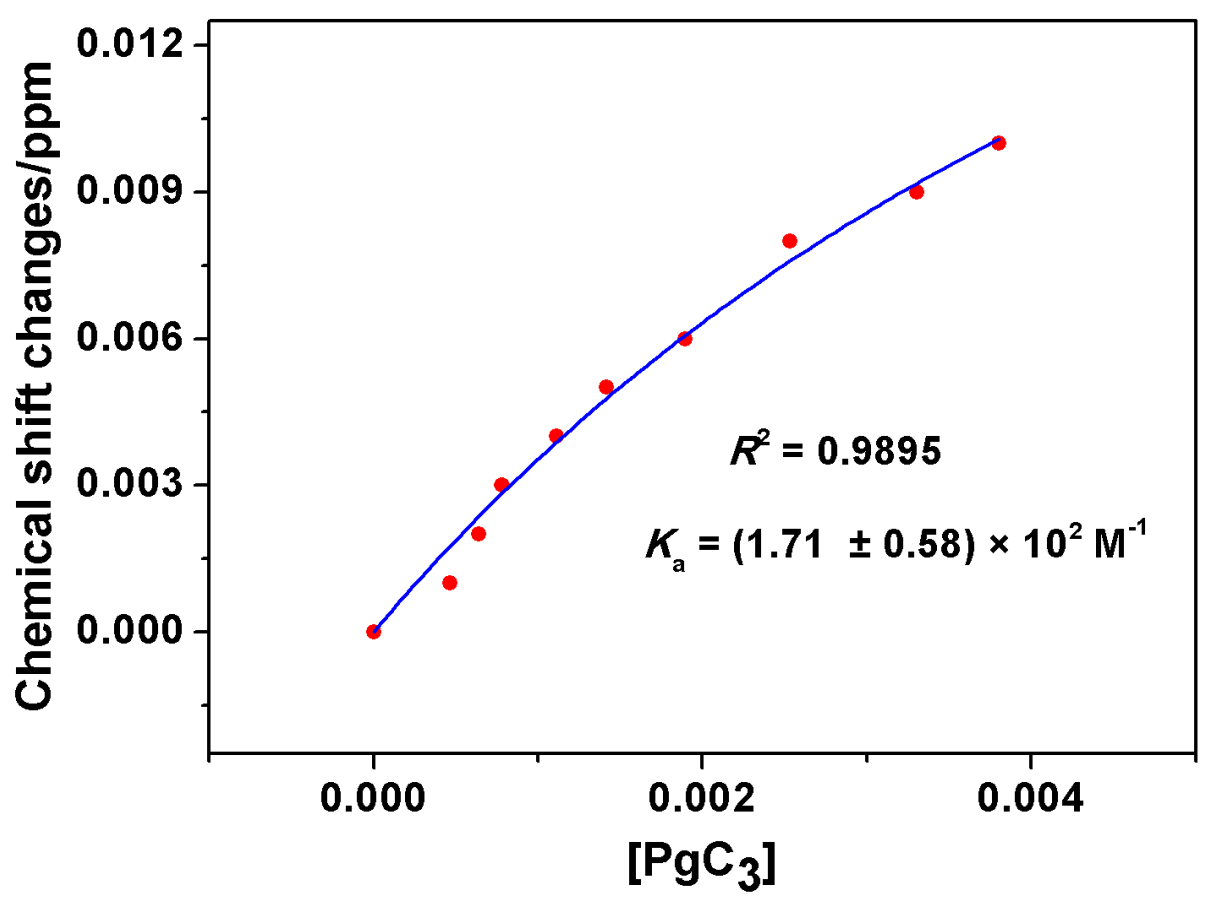

Figure S27. The chemical shift changes of protons $\mathrm{H}_{\mathrm{c}}$ on $\mathbf{P g C}_{3}$ upon addition of DEG in $\mathrm{CD}_{3} \mathrm{CN}$. The blue solid line was obtained from the non-linear curve-fitting using Eq. S1.

8. The 2D NMR NOESY spectrum of PEG and $\boldsymbol{P g C}_{3}$

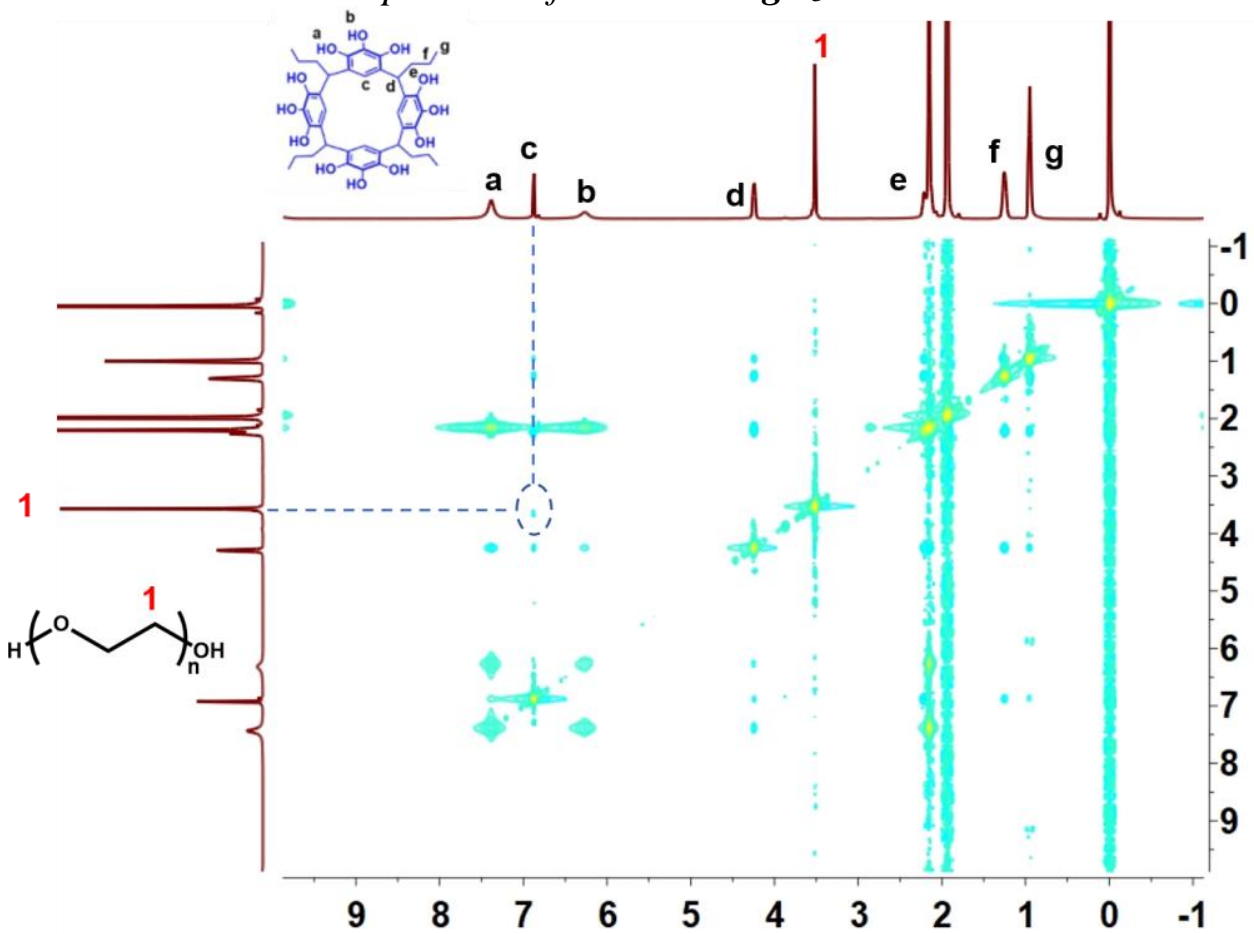

Figure S28. The NOESY spectrum $\left(500 \mathrm{MHz}, \mathrm{CD}_{3} \mathrm{CN}\right.$, rt $)$ of a $0.50 \mathrm{~mL}$ solution containing $1.50 \mathrm{mg}$ PEG2000 and $6.00 \mathrm{mg} \mathbf{P g C}_{\mathbf{3}}$. 
9. ITC investigations of host-guest complexation between PEG and $P_{\mathbf{S}} C_{3}$

Time (min)

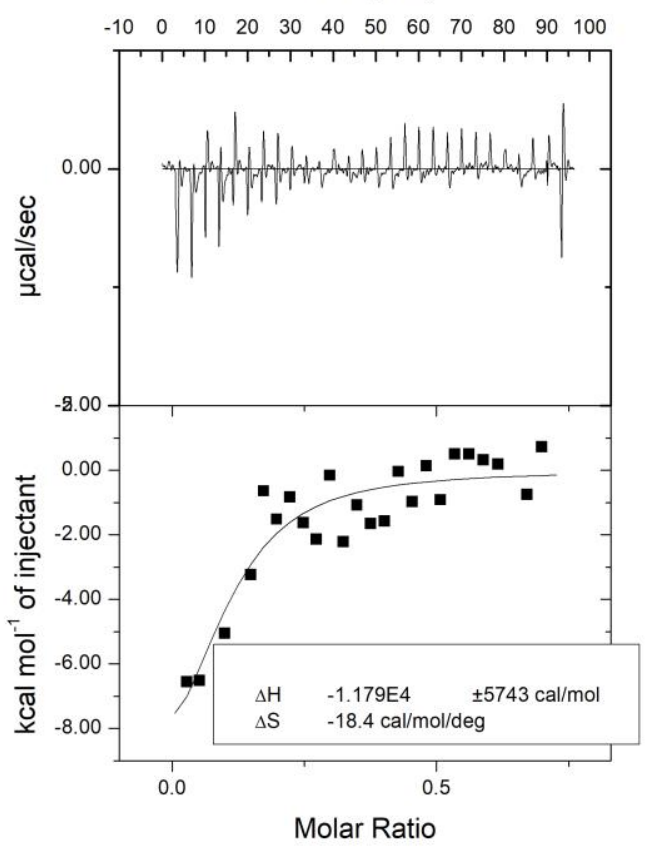

Figure S29. ITC investigations of host-guest complexation between PEG2000 and $\mathbf{P g C}_{3}$ at $298.15 \mathrm{~K}$.

10. Crystal structures of $P g C_{3} \supset E G, P g C_{3} \supset T E G$ and $P g C_{3} \supset$ TetraEG

(a)

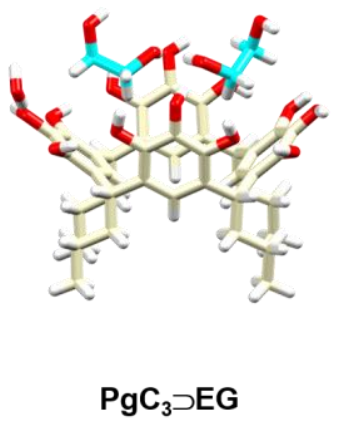

(b)

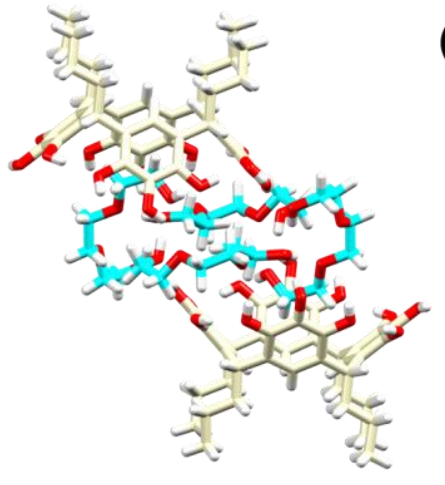

$\mathrm{PgC}_{3} \supset \mathrm{TEG}$ (c)

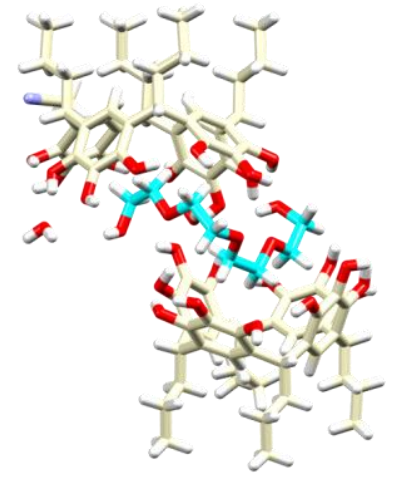

$\mathrm{PgC}_{3} \supset$ TetraEG

Figure S30. Crystal structures of (a) $\mathbf{P g C}_{3} \supset \mathbf{E G}$, (b) $\mathbf{P g C}_{3} \supset$ TEG and (c) $\mathbf{P g C}_{3} \supset$ TetraEG.

\section{Packing model of $\boldsymbol{P g} \boldsymbol{C}_{3}$ in the crystal structure}




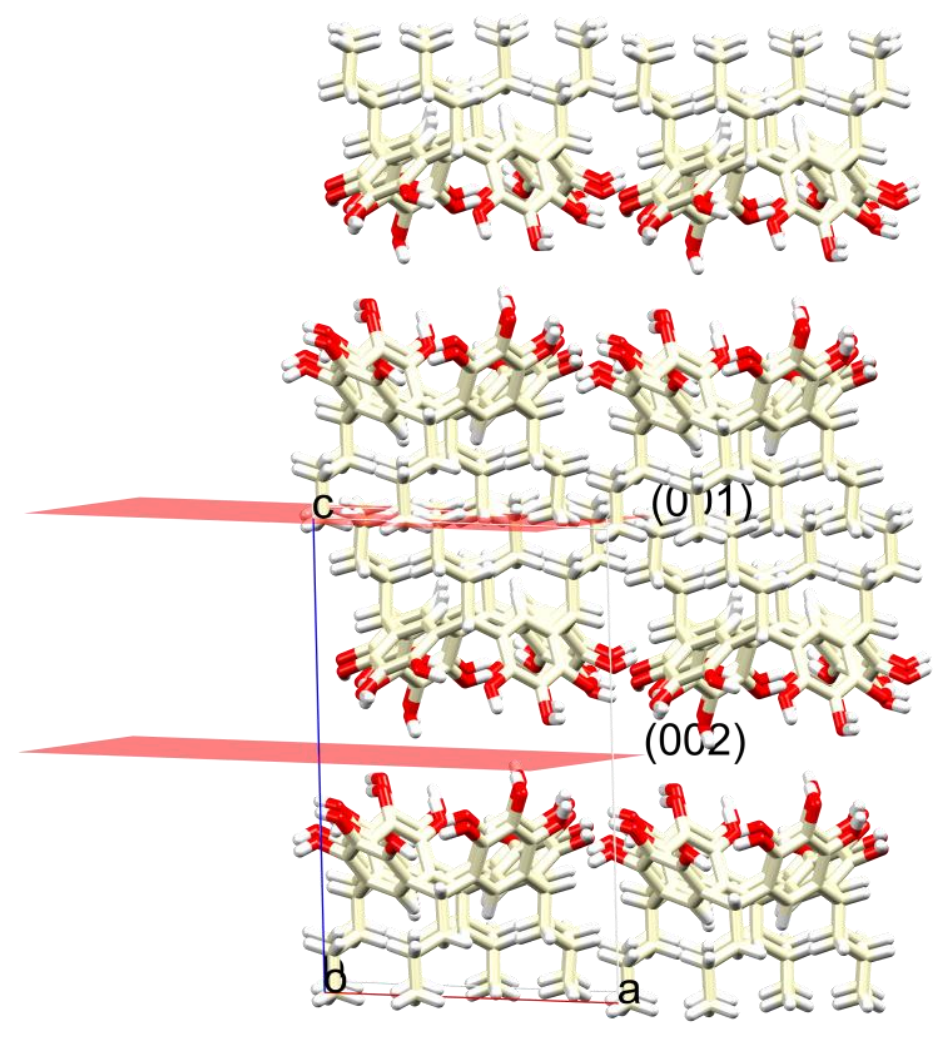

Figure S31. Packing model of $\mathbf{P g C}_{3}$ in the crystal structure. CCDC number 170259. ${ }^{\text {[S9] }}$

12. Time-dependent ${ }^{1} \mathrm{H} N \mathrm{~N}$ R of $\mathrm{PEG}$ with different molecular weights in $\mathrm{D}_{2} \mathrm{O}$ in the presence of $\boldsymbol{P g C}$.

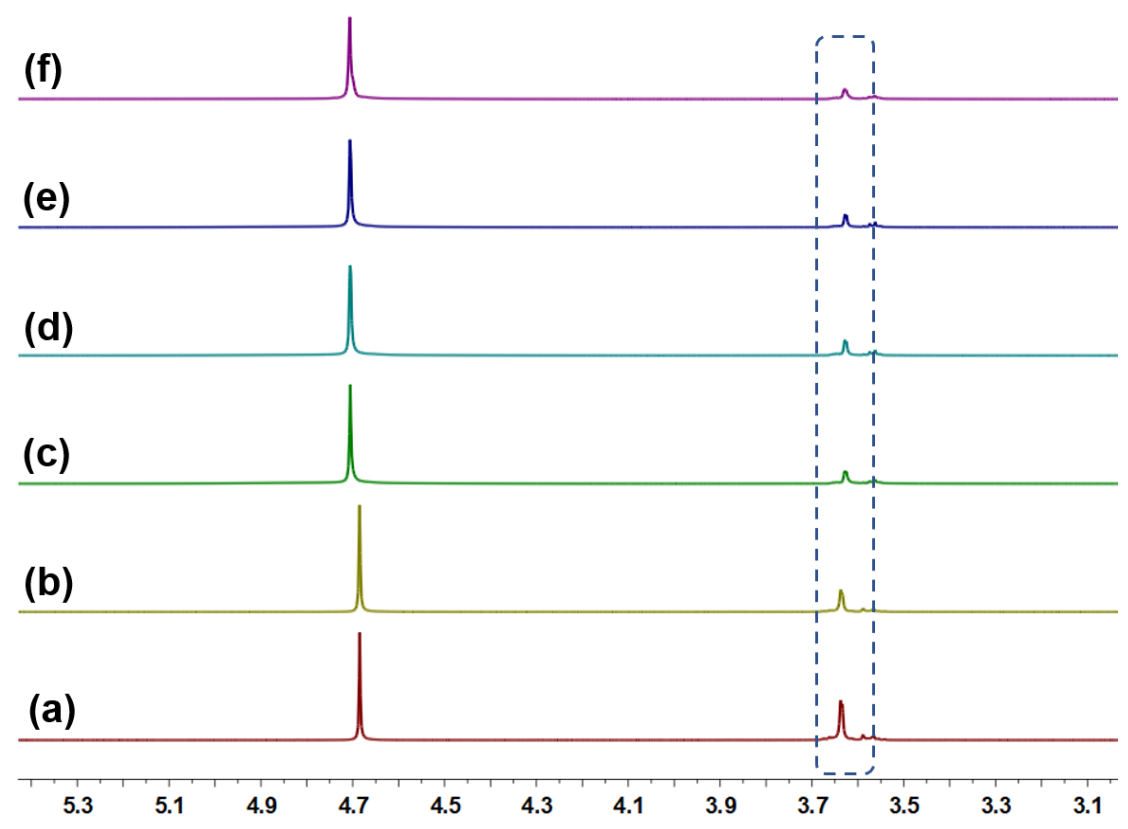

Figure S32. Time-dependent ${ }^{1} \mathrm{H}$ NMR spectra of PEG400 in $\mathrm{D}_{2} \mathrm{O}$ in the presence of PgC 3 : (a) 0; (b) $1 \mathrm{~h}$; (c) $2 \mathrm{~h}$; (d) $8 \mathrm{~h}$; (e) $12 \mathrm{~h}$; (f) $24 \mathrm{~h}$. 


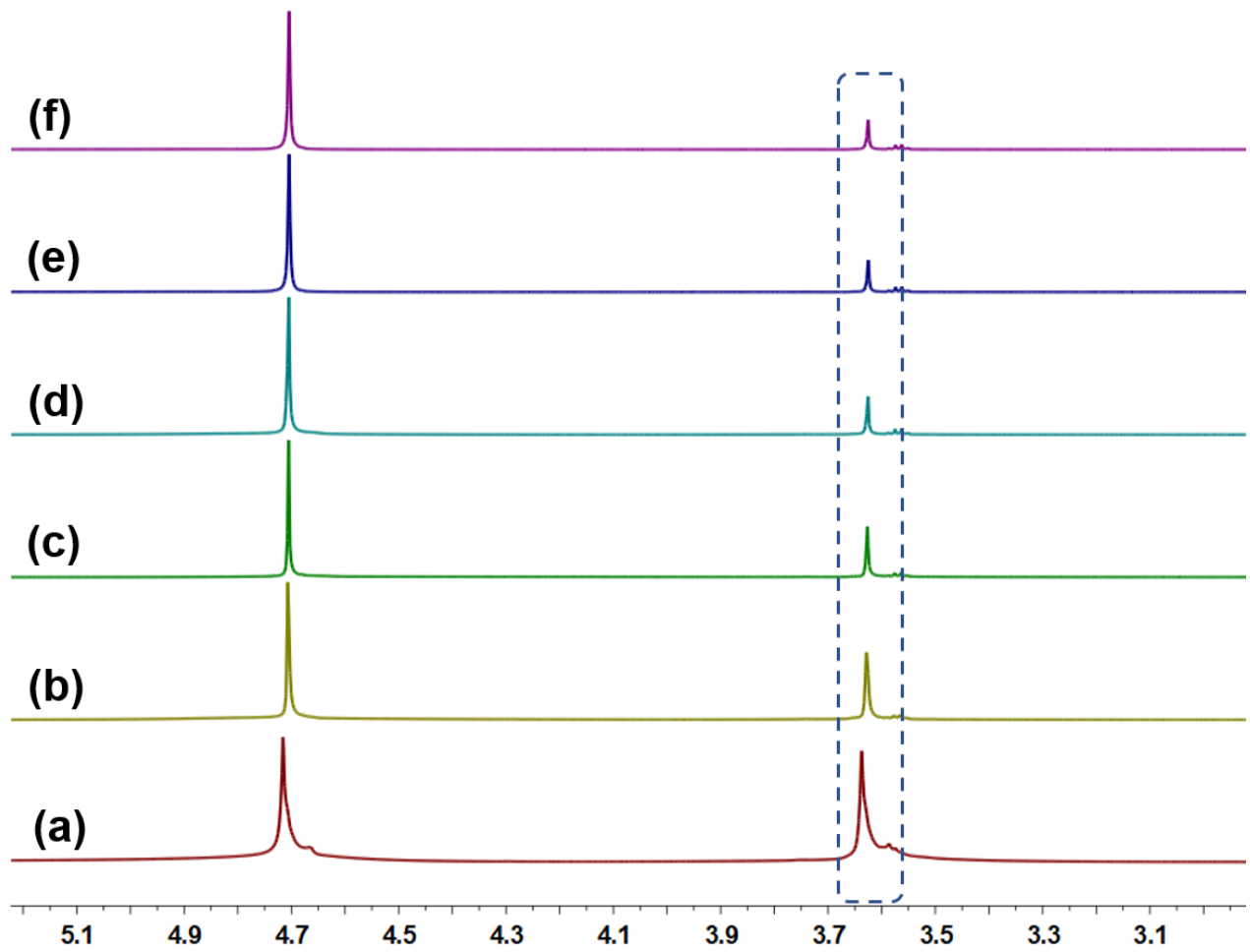

Figure S33. Time-dependent ${ }^{1} \mathrm{H}$ NMR spectra of PEG2000 in $\mathrm{D}_{2} \mathrm{O}$ in the presence of PgC $_{3}$ : (a) 0; (b) $1 \mathrm{~h}$; (c) $2 \mathrm{~h}$; (d) $8 \mathrm{~h}$; (e) $12 \mathrm{~h}$; (f) $24 \mathrm{~h}$.

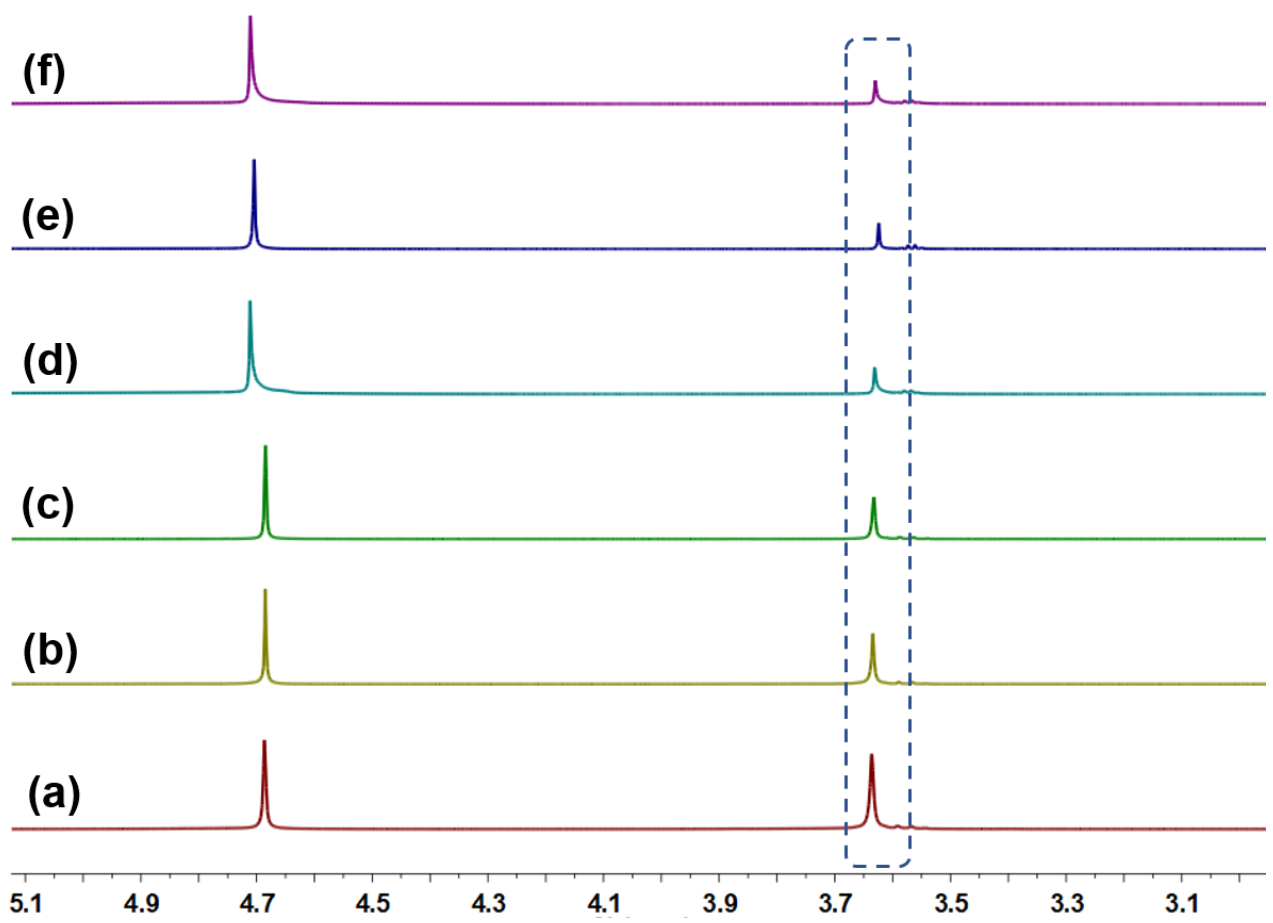

Figure S34. Time-dependent ${ }^{1} \mathrm{H}$ NMR spectra of PEG4000 in $\mathrm{D}_{2} \mathrm{O}$ in the presence of PgC : (a) 0; (b) 1 h; (c) 2 h; (d) 8 h; (e) 12 h; (f) 24 h. 


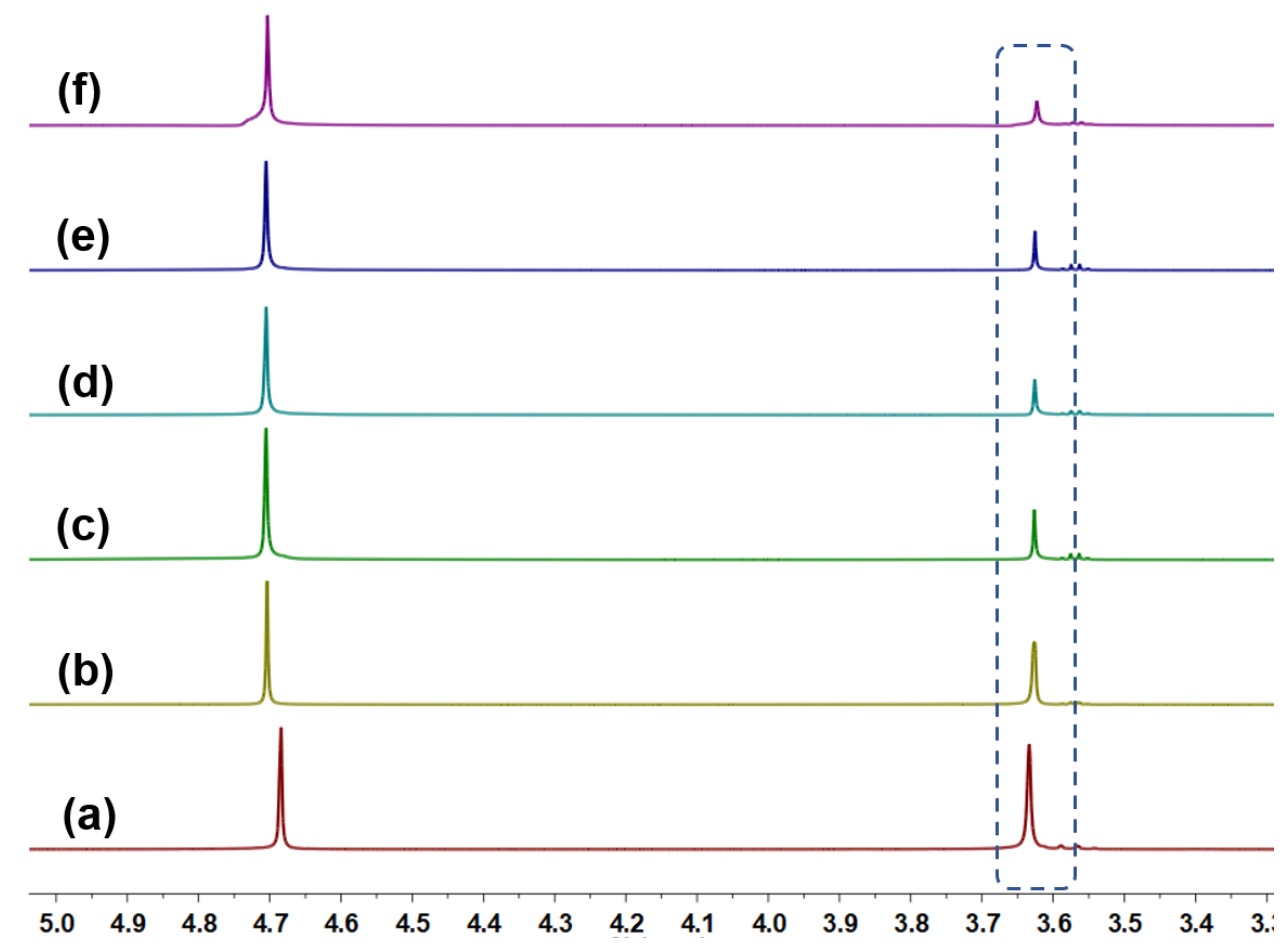

Figure S35. Time-dependent ${ }^{1} \mathrm{H}$ NMR spectra of PEG6000 in $\mathrm{D}_{2} \mathrm{O}$ in the presence of PgC : (a) 0; (b) 1 h; (c) 2 h; (d) 8 h; (e) 12 h; (f) 24 h.

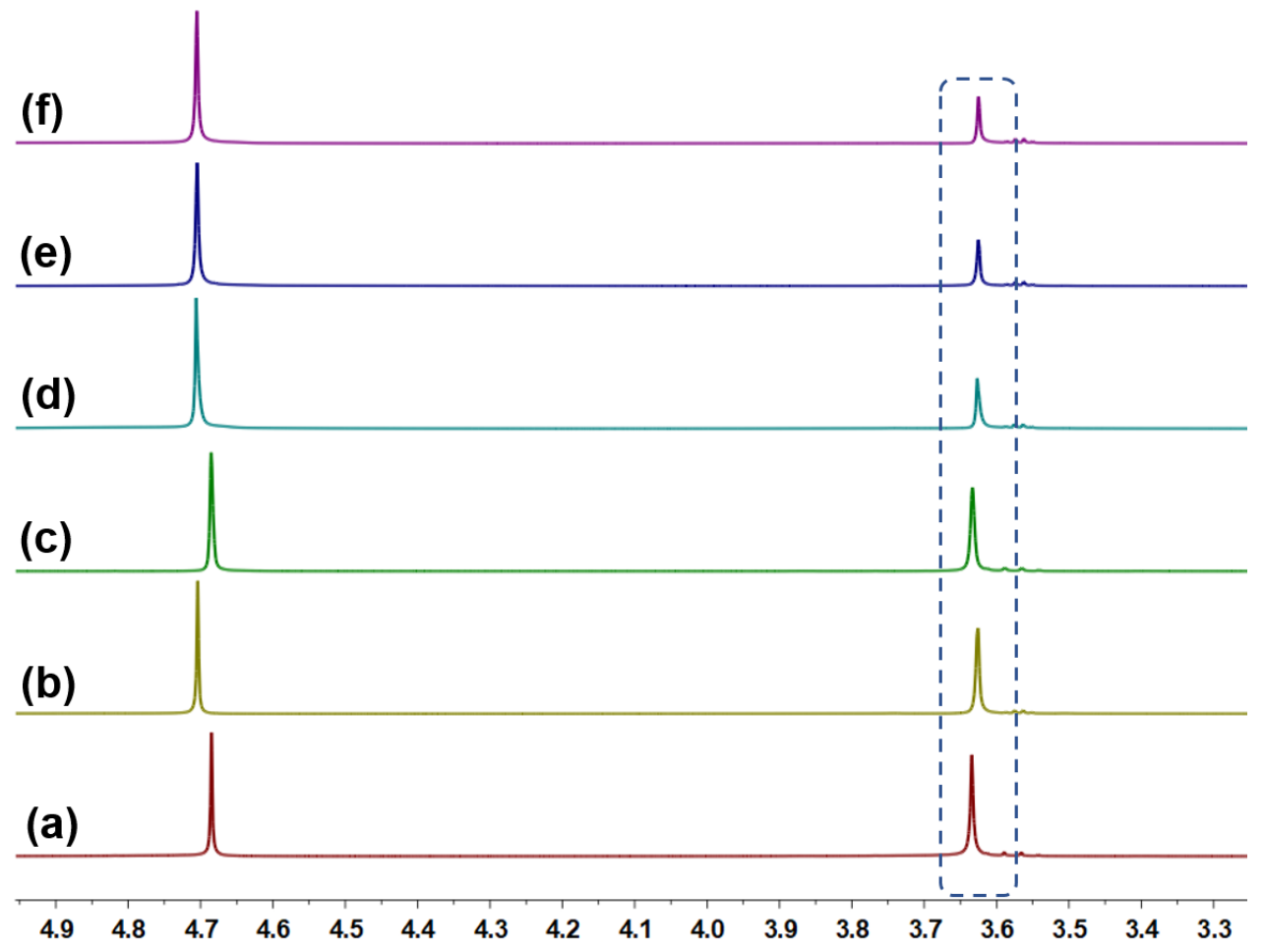

Figure S36. Time-dependent ${ }^{1} \mathrm{H}$ NMR spectra of PEG8000 in $\mathrm{D}_{2} \mathrm{O}$ in the presence of PgC : (a) 0; (b) 1 h; (c) 2 h; (d) 8 h; (e) 12 h; (f) 24 h. 


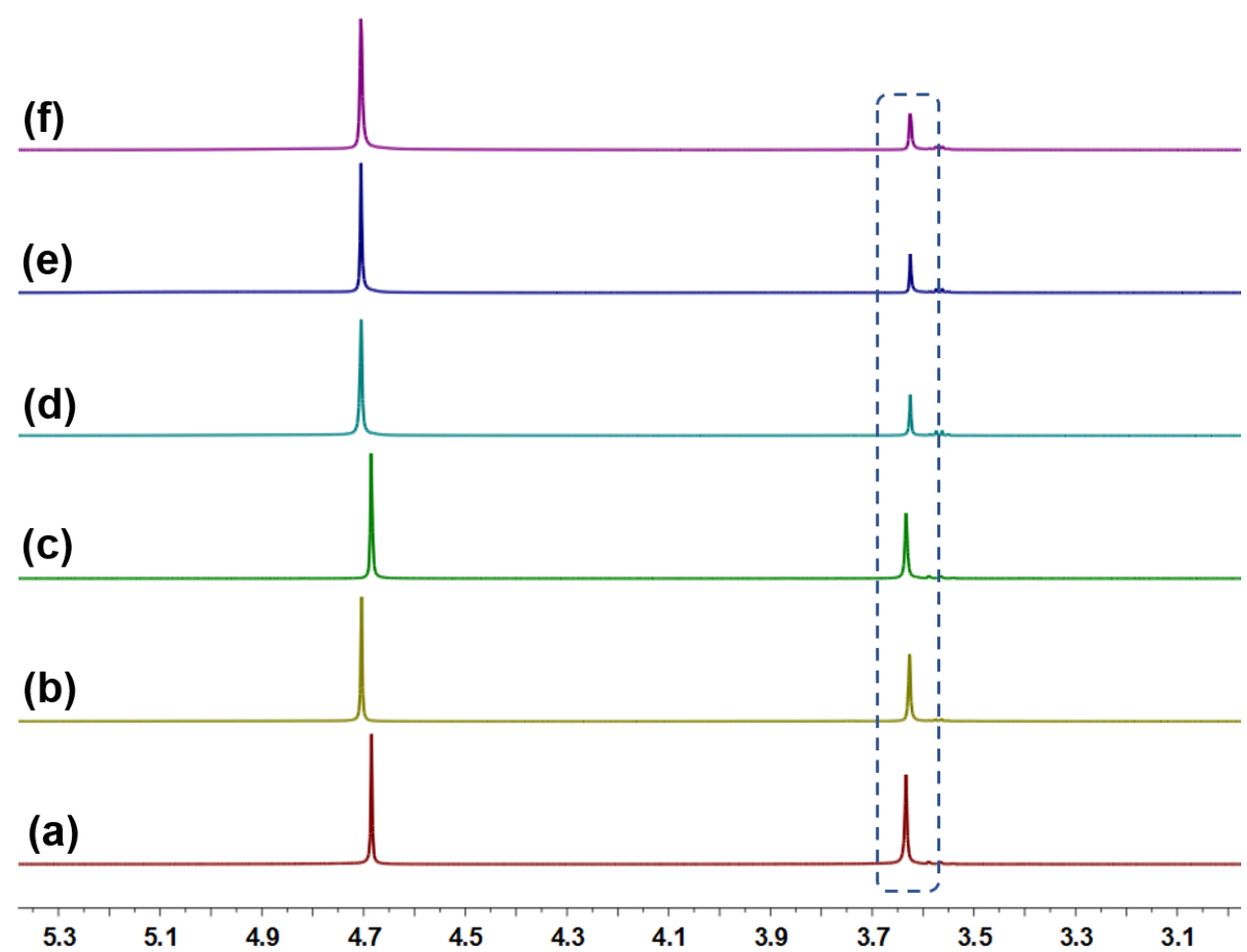

Figure S37. Time-dependent ${ }^{1} \mathrm{H}$ NMR spectra of PEG10000 in $\mathrm{D}_{2} \mathrm{O}$ in the presence of PgC 3 : (a) 0; (b) $1 \mathrm{~h}$; (c) $2 \mathrm{~h}$; (d) $8 \mathrm{~h}$; (e) $12 \mathrm{~h}$; (f) $24 \mathrm{~h}$.

13. X-ray crystal data of $P g C_{3} \supset E G, P g C_{3} \supset T E G$ and $P g C_{3} \supset$ TetraEG

\begin{tabular}{|c|c|c|c|}
\hline Formula & PgC $_{3} \supset \mathbf{E G}$ & PgC $_{3} \supset$ TEG & PgC $_{3} \supset$ TetraEG \\
\hline Crystallization Solvent & acetonitrile & acetonitrile & acetonitrile \\
\hline Collection Temperature & $100 \mathrm{~K}$ & $296.15 \mathrm{~K}$ & $298 \mathrm{~K}$ \\
\hline Sum Formula & $\mathrm{C}_{40} \mathrm{H}_{48} \mathrm{O}_{12}$ & $\mathrm{C}_{52} \mathrm{H}_{76} \mathrm{O}_{20}$ & $\mathrm{C}_{90} \mathrm{H}_{122} \mathrm{NO}_{32}$ \\
\hline$M r$ & 853.92 & 1021.12 & 1721.88 \\
\hline Crystal Size $[\mathrm{mm}]$ & $0.29 \times 0.23 \times 0.1$ & $0.48 \times 0.25 \times 0.2$ & $0.12 \times 0.11 \times 0.1$ \\
\hline Crystal System & monoclinic & triclinic & monoclinic \\
\hline Space Group & $\mathrm{C} 2 / \mathrm{c}$ & $\mathrm{P}-1$ & $\mathrm{P}_{1} / \mathrm{n}$ \\
\hline$a[\AA]$ & $45.4178(15)$ & $13.0619(12)$ & $11.6204(7)$ \\
\hline$b[\AA]$ & $9.3163(3)$ & $17.9017(17)$ & $23.4636(12)$ \\
\hline$c[\AA]$ & $23.3301(2)$ & $22.873(2)$ & $35.458(2)$ \\
\hline$\alpha\left[^{\circ}\right]$ & 90 & $103.460(2)$ & 90 \\
\hline$\beta\left[^{\circ}\right]$ & $119.415(2)$ & $101.469(2)$ & $96.637(2)$ \\
\hline$\gamma\left[{ }^{\circ}\right]$ & 90 & $91.663(2)$ & 90 \\
\hline$V\left[\AA^{3}\right]$ & $8599.0(5)$ & $5081.6(8)$ & $9603.0(10)$ \\
\hline$Z$ & 8 & 4 & 4 \\
\hline$D c a l c d\left[\mathrm{~g} \mathrm{~cm}^{-3}\right]$ & 1.319 & 1.335 & 1.191 \\
\hline$\mu\left[\mathrm{mm}^{-1}\right]$ & 0.838 & 0.102 & 0.090 \\
\hline
\end{tabular}




\begin{tabular}{|c|c|c|c|}
\hline $\mathrm{F}(000)$ & 3656.0 & 2192.0 & 3684.0 \\
\hline $2 \theta$ range $\left[^{\circ}\right]$ & $7.58-148.62$ & $2.346-63.646$ & $3.932-55.054$ \\
\hline Reflections collected & 105124 & 227305 & 89847 \\
\hline Independent reflections, Rint & $8569,0.0650$ & $34510,0.0358$ & $22028,0.0957$ \\
\hline Data /restraints /parameters & $8569 / 0 / 601$ & $34510 / 4 / 1433$ & $22028 / 156 / 1215$ \\
\hline Final $R 1$ values $(I>2 \sigma(I))$ & 0.0681 & 0.0552 & 0.0819 \\
\hline Final $R 1$ values (all data) & 0.0724 & 0.0793 & 0.1583 \\
\hline Final $w R\left(F_{2}\right)$ values (all data) & 0.1827 & 0.1666 & 0.2659 \\
\hline Goodness-of-fit on $F^{2}$ & 1.122 & 1.029 & 1.036 \\
\hline $\begin{array}{c}\text { Largest difference peak and } \\
\text { hole }\left[\mathrm{e} . \mathrm{A}^{-3}\right]\end{array}$ & $0.74 /-0.33$ & $0.97 /-0.75$ & $1.10 /-0.56$ \\
\hline CCDC & 2033979 & 2033980 & 2033981 \\
\hline
\end{tabular}

\section{References}

S1. Zhang C.; Patil S. R.; Li T.; Barnes L. C.; Teat J. S.; Atwood L. J. Preparation of Magnesium-Seamed C-Alkylpyrogallol[4]arene Nanocapsules with Varying Chain Lengths. Chem. Eur. J. 2017, 23, 8520-8524.

S2. Apex3, AXScale, and SAINT, version 2017.3-0, Bruker AXS, Inc., Madison, WI, 2017.

S3. Sheldrick, G. M. SHELXS, v.2013-1, 2013.

S4. Sheldrick, G. M. SHELXT - Integrated space-gropu and crystal-structure determination. Acta Cryst. Sect. A: Found. Adv. 2015, 71, 3-8.

S5. Dolomanov, O.V.; Bourhis, L.J.; Gildea, R.J.; Howard, J.A.K.; Puschmann, H. OLEX2: A complete structure solution, refinement, and analysis program. J. Appl. Cryst. 2009, 42, 339-341.

S6. Macrae, C. F.; Bruno, I. J.; Chisholm, J. A.; Edgington, P. R.; McCabe, P.; Pidcock, E.; Rodriguez-Monge, L.; Taylor, R.; van de Streek, J.; Wood, P. A. Mercury CSD 2.0 - New features for the visualization and investigation of crystal structures. J. Appl. Cryst. 2008, 41, 466-470.

S7. Thordarson, P. Determining association constants from titration experiments in supramolecular chemistry. Chem. Soc. Rev. 2011, 40, 1305-1323.

S8. Yu, G.; Han, C.; Zhang, Z.; Chen, J.; Yan, X.; Zheng, B.; Liu, S.; and Huang, F. Pillar[6]arene-Based Photoresponsive Host-Guest Complexation. J. Am. Chem. Soc. 2012, 134, 8711-8717.

S9. Shivanyuk, A.; Rebek, J. J. Hydrogen-bonded capsules in polar, protic solvents. Chem. Commun. 2001, 2374-2375. 